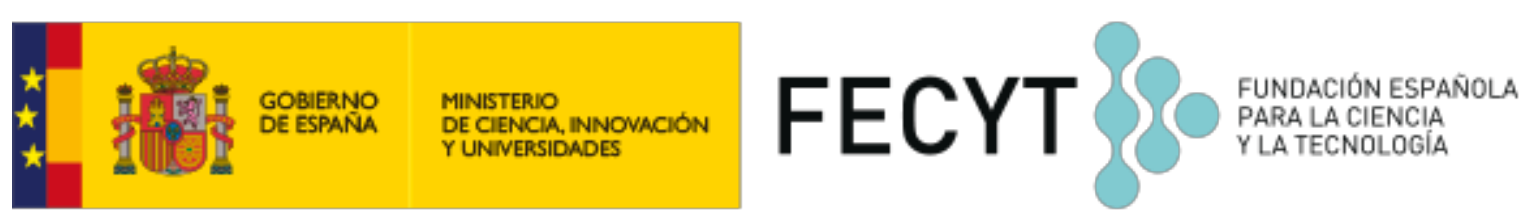

\title{
Research Intelligence
}

\section{Scopus}

Versión: Abril 2019

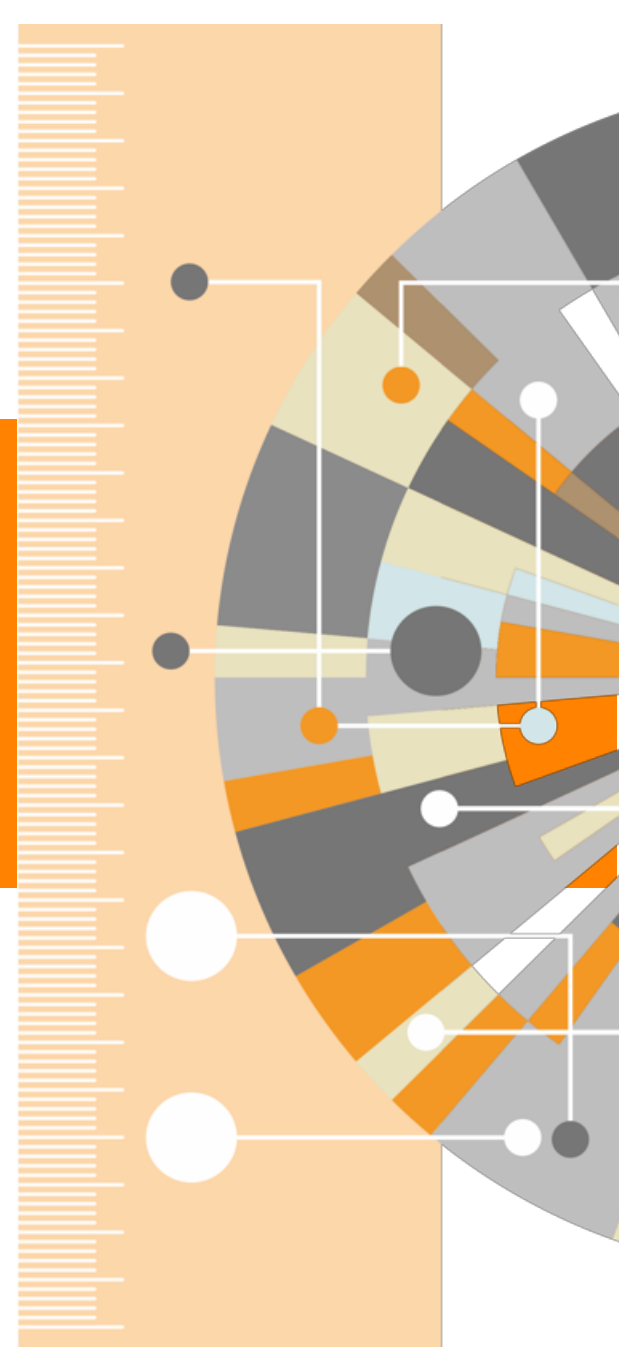




\section{Indice}

- ¿Qué es Scopus?

- Apoyo a investigadores y bibliotecarios

- Datos de Scopus:

- Métodos de distribución, The Gold Standard (Rankings, THE, National Assessment)

- Contenido de Scopus:

- Representación global, profundidad histórica de contenido

- Mantenimiento de Alta Calidad, Content Selection Advisory Board y criterios de selección y reevaluación

- Cómo acceder a Scopus:

- Registro y creación de un Perfil Personal y Ajustes

- Búsqueda de Documentos y Avanzada

- Perfiles de Scopus

- Búsqueda de Autor

- Búsqueda de Afiliación

- Métricas de Investigación

- Sources y Comparador de Fuentes

- Journal Metrics CiteScore, SNIP, SJR

- PlumX

- Más información 
Scopus es la mayor base de datos de resúmenes y citas de la literatura revisada por pares; cuenta con herramientas inteligentes que permiten controlar, analizar y visualizar la investigación académica.

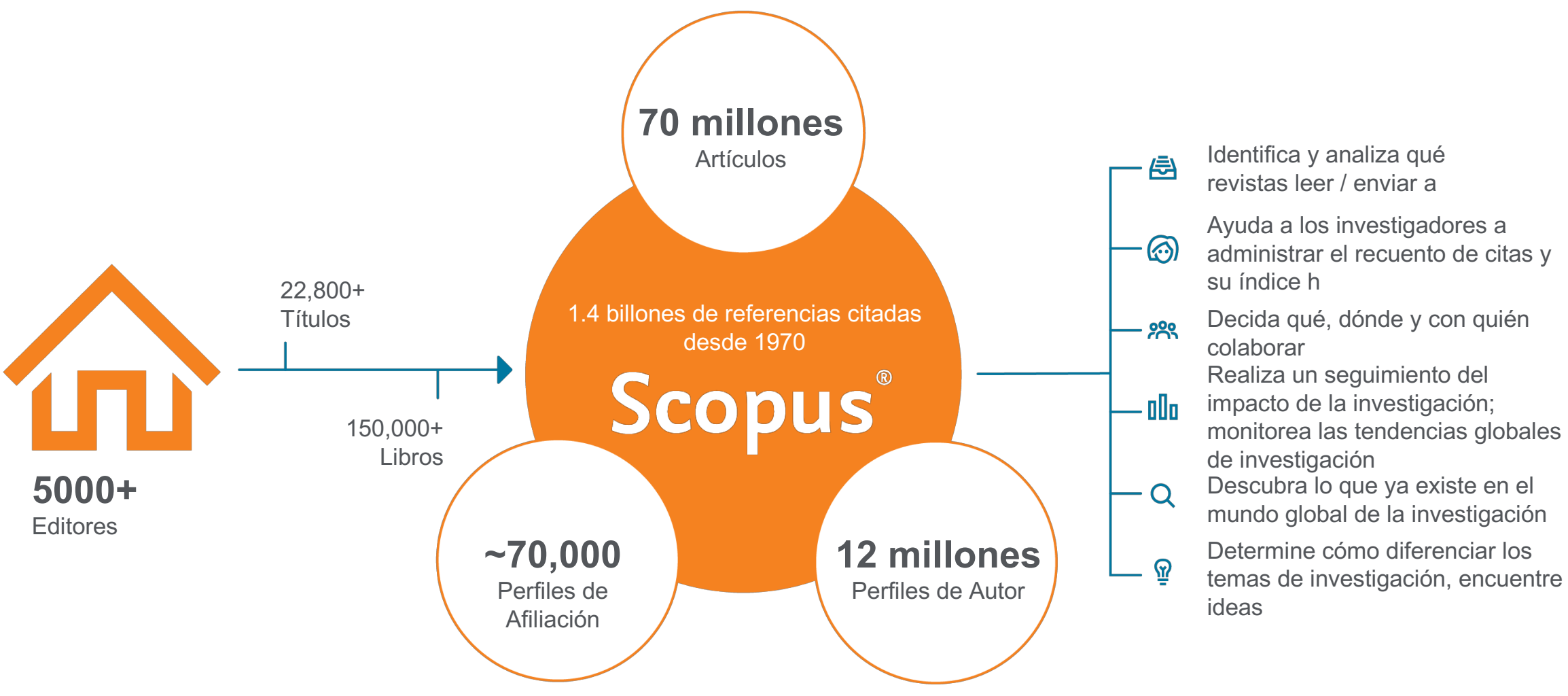

Scopus ofrece una visión completa del mundo de la investigación. Sin paquetes, sin complementos. Una suscripción con todo incluido. 
Apoyo a Investigadores 


\section{Scopus ayuda a los investigadores a tener éxito}

Como investigador, se enfrenta a muchos desafíos. La competencia es global y las fuentes de financiación cambian constantemente. La tecnología está transformando la forma de trabajar en el laboratorio y la forma de colaborar con sus compañeros - que abarcan continentes e incluso disciplinas. Y mientras que usted está tratando de lograr el próximo gran avance científico, la gestión de su carrera se ha convertido en un trabajo a tiempo completo. Scopus le ayudará a tener éxito en este sistema ecológico global de investigación en evolución. Scopus se encuentra presente en el $84 \%$ de las mejores universidades.

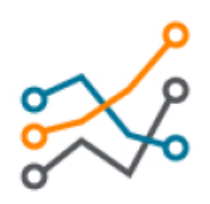

Siga tendencias

importantes y emergentes

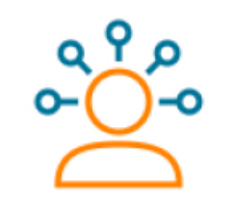

Haga su investigación

más visible

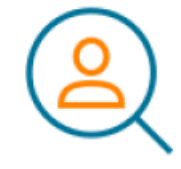

Descubra nuevos

colaboradores

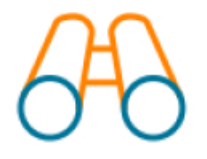

Analice el panorama de

la investigación 
Apoyo a Bibliotecarios 


\section{Potencie el futuro de la investigación con Scopus}

Scopus está aquí para ayudar. Para sus usuarios, ofrecemos acceso inigualable a conocimientos y análisis de investigación críticos, para que puedan tener éxito en un ecosistema de investigación global. Para usted, proporcionamos una solución fácil de administrar con el mejor modelo de datos para enlaces de autorinstitución-artículo y robustas integraciones de API para sus recursos y sistemas, sin los modelos de suscripción complejos o modulares que a menudo se encuentran con otros recursos de bases de datos. Scopus también proporciona informes de uso para sus evaluaciones de ROI y datos que lo ayudan a analizar las tendencias y el rendimiento de la investigación institucional. Desde ayudarle a brindar las mejores experiencias de investigación en su clase hasta elevar sus discusiones y relaciones con sus partes interesadas, Scopus le brinda los conocimientos y las herramientas para impulsar el futuro de la investigación en su institución.

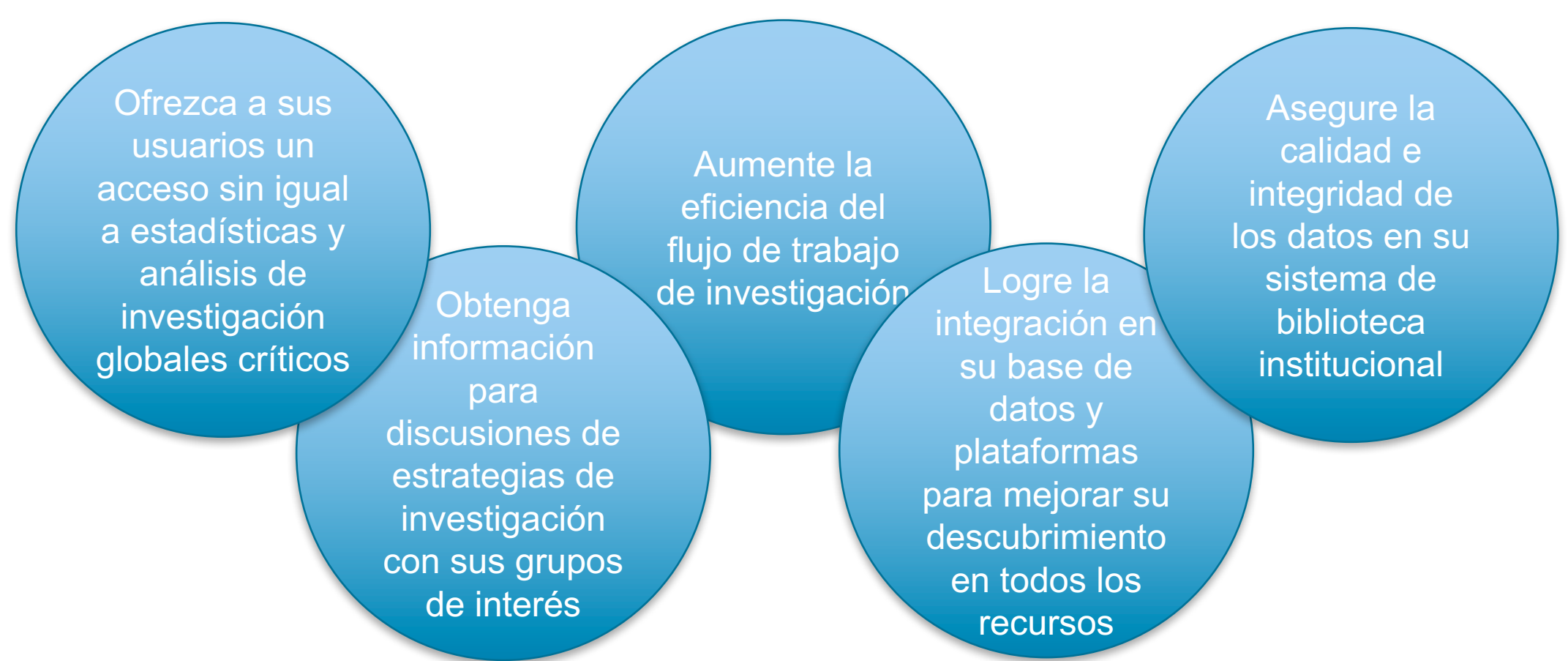


Datos de Scopus 


\section{Datos de Scopus: líder en calidad y cantidad}

\section{Un mundo de Datos para explorar}

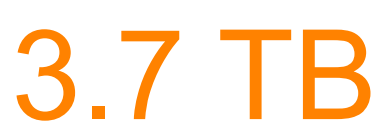

Datos almacenados en repositorio de contenido

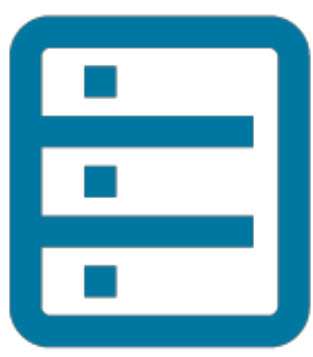

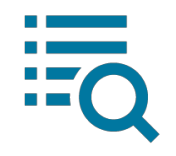

1.4 billones

Referencias citadas

䍏

70,000

perfiles institucionales

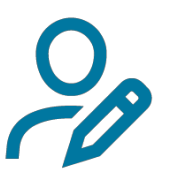

\section{2 millones}

perfiles de autor

Scopus entrega todos los metadatos proporcionados por los editores, que incluyen: "autor (es), afiliación (es), título del documento, año, identificación eléctrica (EID), título fuente, volumen / número / páginas, recuento de citas, fuente, tipo de documento e identificador de objeto digital (DOI). 


\section{Datos de Scopus: Gold Standard}

\section{El Gold Standard}

Scopus es seleccionado por su excelencia por:

4,500

Universidades

150

Organizaciones líderes en investigación

Quienes continúan eligiendo Scopus para fines de evaluación y evaluación de investigación sobre cualquier otro competidor
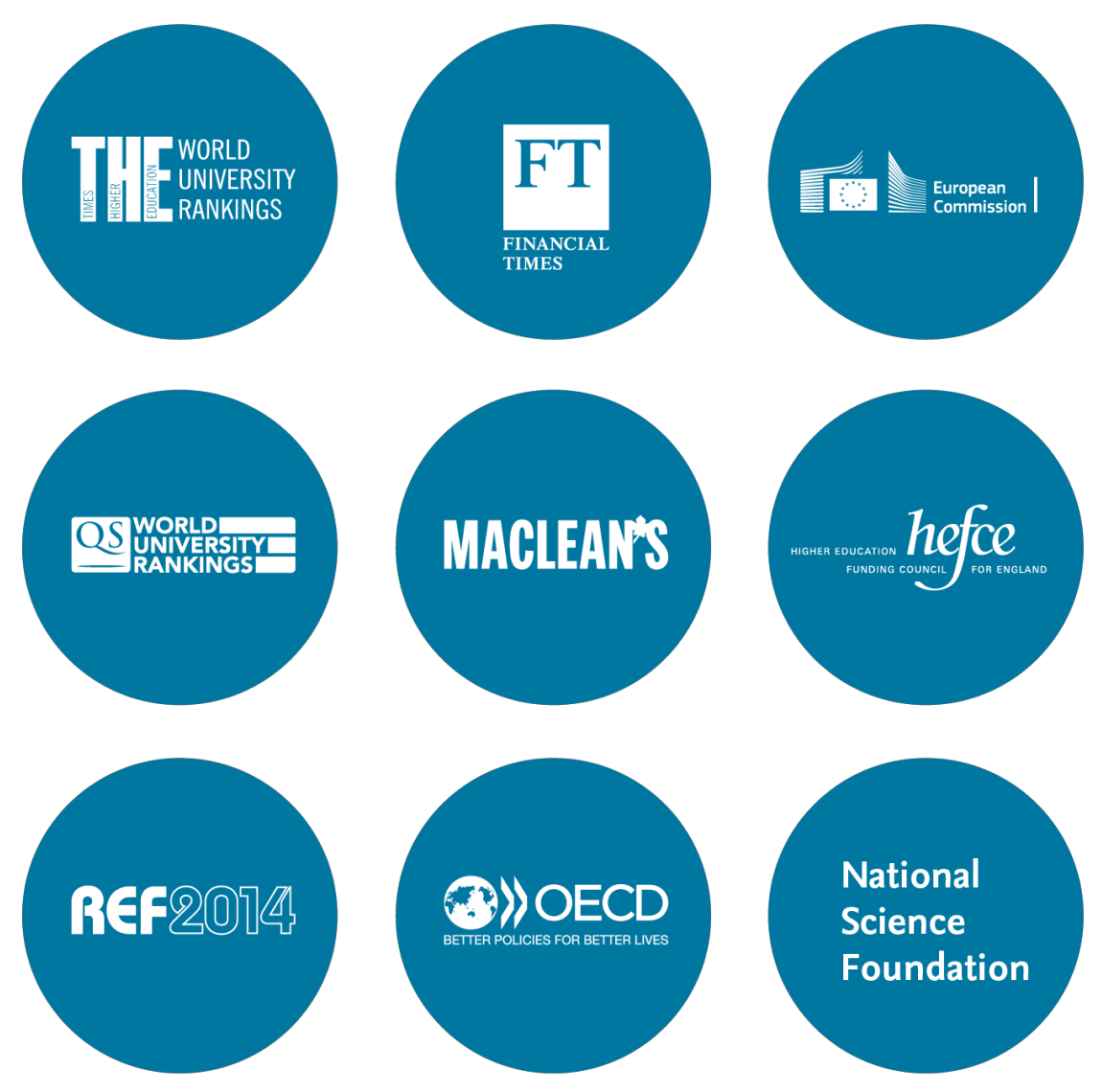


\section{Scopus is the Gold Standard:}

Evaluation, ranking, reporting, landscape analysis and other strategic efforts

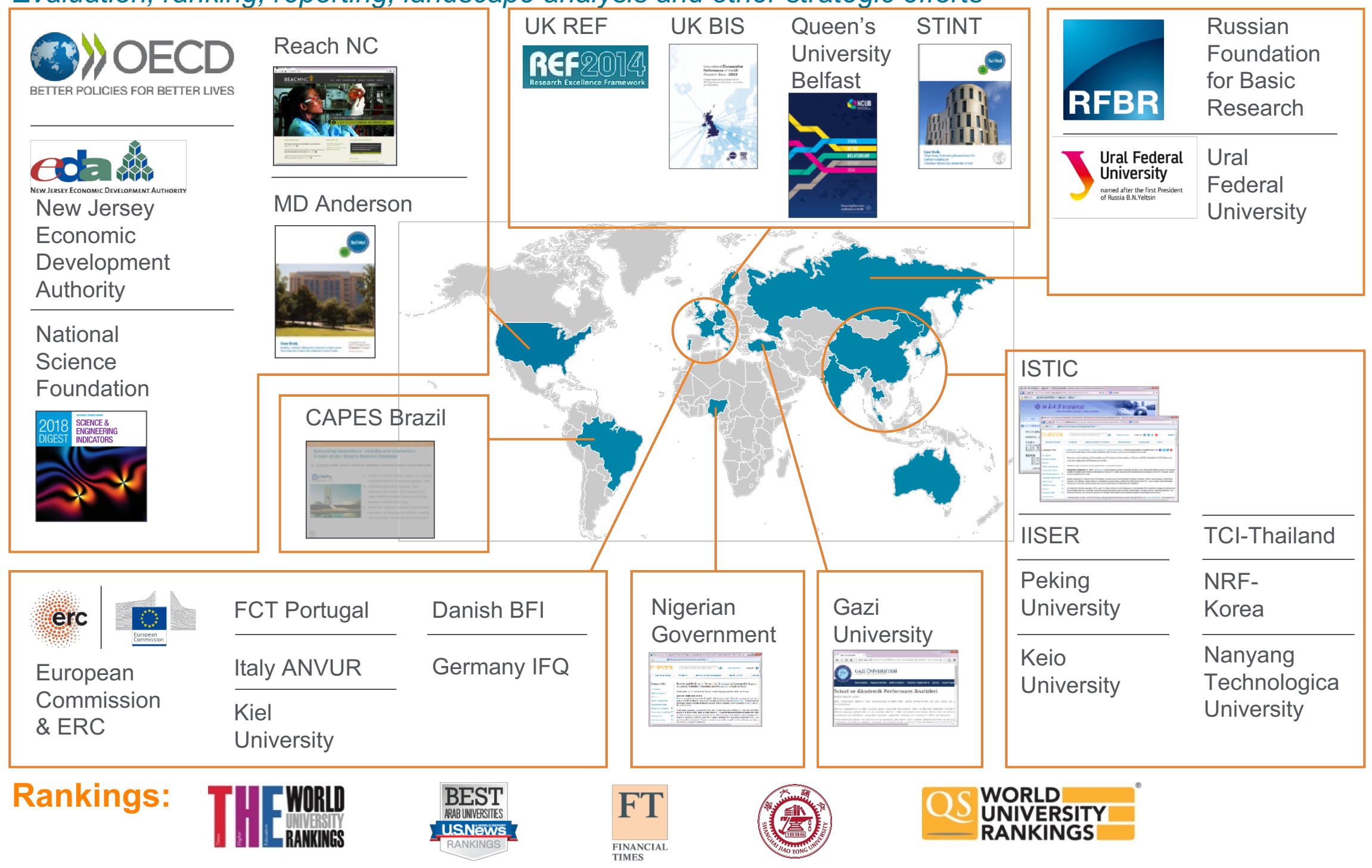




\section{Apoyo a proyectos de investigación, integración y análisis Los datos de Scopus se distribuyen de tres maneras:}

\begin{tabular}{|c|c|c|c|}
\hline Scopus.com & $\begin{array}{l}\text { ¿Qué? } \\
\text { La base de datos } \\
\text { de citas y reseñas } \\
\text { más grande del } \\
\text { mundo de literatura } \\
\text { revisada por pares }\end{array}$ & $\begin{array}{l}\text { ¿Cómo? } \\
\text { Los usuarios acceden } \\
\text { al contenido de } 5000 \\
\text { editores directamente } \\
\text { con herramientas de } \\
\text { descubrimiento y } \\
\text { analíticas }\end{array}$ & $\begin{array}{l}\text { ¿Por qué? } \\
\text { Ninguna otra } \\
\text { herramienta puede } \\
\text { decirle quién y dónde } \\
\text { está haciendo ciencia } \\
\text { mejor que Scopus }\end{array}$ \\
\hline Scopus API & $\begin{array}{l}\text { ¿Qué? } \\
\text { Manera en que el } \\
\text { sistema de un } \\
\text { cliente solicita } \\
\text { datos a Scopus en } \\
\text { tiempo real }\end{array}$ & $\begin{array}{l}\text { ¿Cómo? } \\
\text { La API es como la } \\
\text { tubería: sin ella, el } \\
\text { cliente no podría } \\
\text { conectarse a nuestro } \\
\text { depósito de datos }\end{array}$ & $\begin{array}{l}\text { ¿Por qué? } \\
\text { El cliente elige la } \\
\text { integración con } \\
\text { programas y } \\
\text { aplicaciones }\end{array}$ \\
\hline Custom Data & $\begin{array}{l}\text { ¿Qué? } \\
\text { Entrega a granel } \\
\text { de datos en forma } \\
\text { (relativamente) } \\
\text { estática }\end{array}$ & $\begin{array}{l}\text { ¿Cómo? } \\
\text { El cliente define la } \\
\text { cantidad de datos } \\
\text { que necesita y } \\
\text { luego lo entrega a } \\
\text { granel. }\end{array}$ & $\begin{array}{l}\text { ¿Por qué? } \\
\text { Datos personalizados } \\
\text { encajan perfectamente si } \\
\text { hay una necesidad de } \\
\text { datos específica y se } \\
\text { controla la forma en que } \\
\text { se analiza }\end{array}$ \\
\hline
\end{tabular}


Contenido de Scopus 


\section{Representación global significa descubrimiento global}

En todas las materias y tipos de contenido

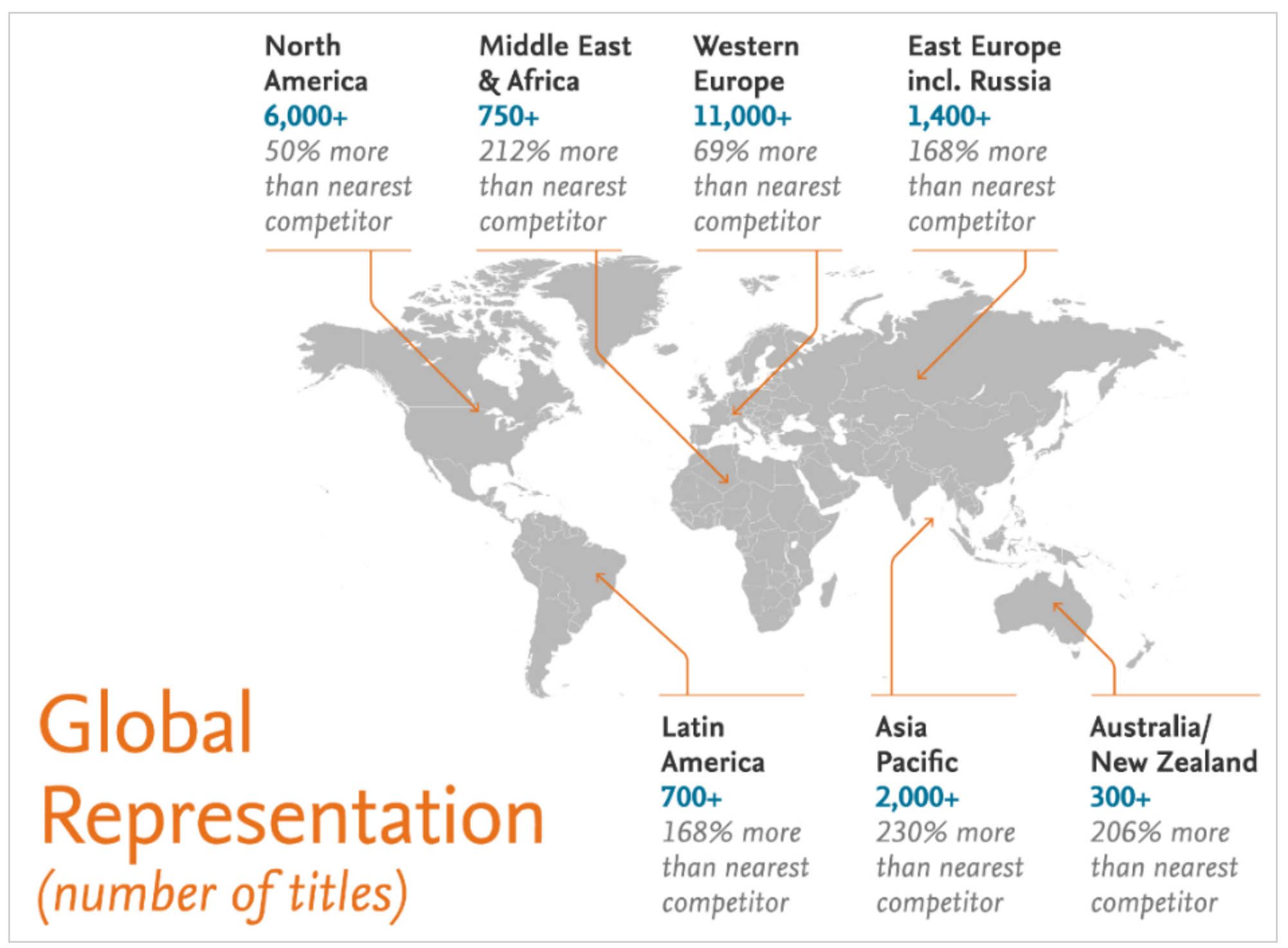




\section{Representación global significa descubrimiento global} En todas las materias y tipos de contenido

\section{Scopus incluye contenido de más de $\mathbf{5 . 0 0 0}$ editores y 105 países diferentes}

- 40 idiomas diferentes cubiertos

- Actualizado a diario

- Múltiples tipos de contenido regional cubiertos (revistas, conferencias, libros, series de libros)

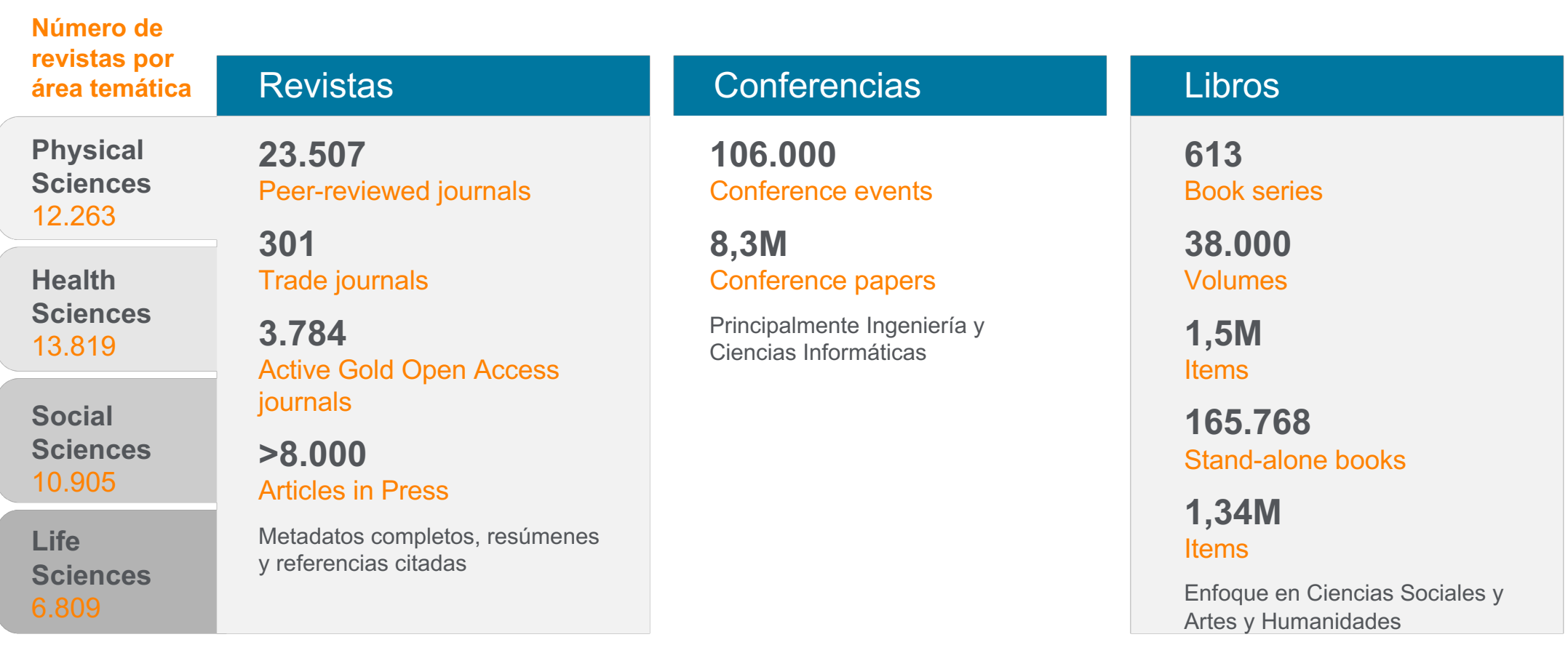




\section{Scopus}

\section{El líder del índexación bibliográfico}

$>70 \mathrm{M}$ registros y más de $\mathbf{2 3 . 5 0 0}$ títulos activos de más de $\mathbf{5 . 0 0 0}$ editores internacionales. Más de 3.759 revistas indexadas de Gold Open Access, 165.000 libros y $8,3 \mathrm{M}$ actas de congresos*

Imparcial, cobertura integral con títulos de revistas de muchas editoriales académicas acreditadas

Scopus ofrece una visión integral del mundo de la investigación

Sin paquetes, ni

complementos.

Una suscripción con todo incluido

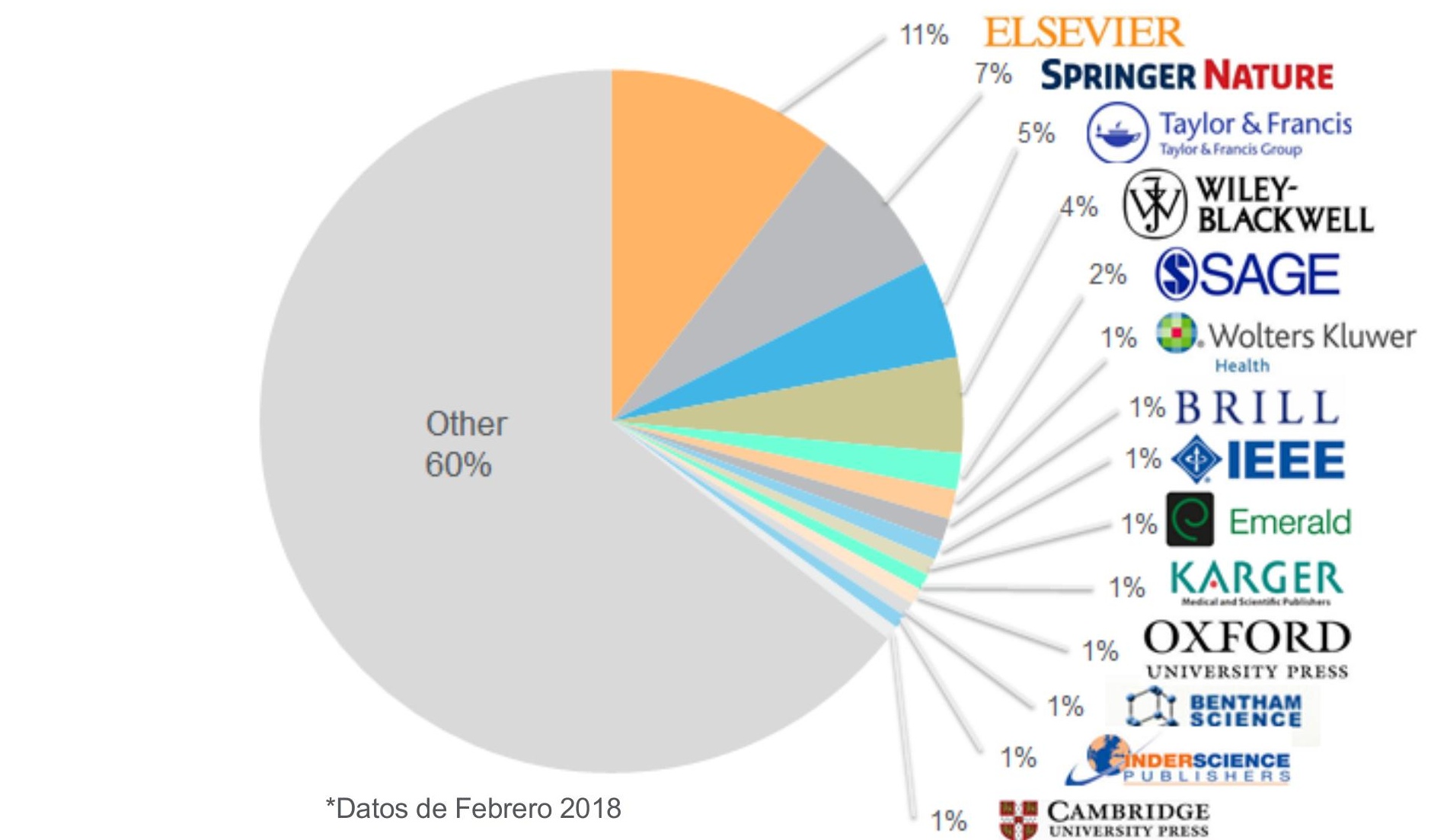




\section{Contenido histórico que se remonta a 1788}

Scopus ofrece una visión integral del mundo de la investigación

Sin paquetes, ni

complementos.

Una suscripción con todo incluido

- En los últimos 3 años, Scopus ha agregado 195 millones de referencias más citadas que datan de 1970, para complementar los registros existentes de la base de datos que datan de 1788 y aumentar aún más la profundidad del contenido.

- Resultados de referencias más citadas en :

- análisis bibliométrico e histórico de tendencias más extensor

- perfiles de autor más completos

- medidas mejoradas de índice h para autores que publicaron antes de 1996

\section{Historical Depth}

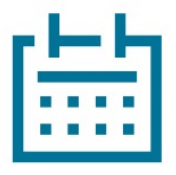

1788

TODAY

Records back to

1788

References are included on records back to

1970
Scopus has recently added 195 million references and now covers 11.5 million records between 1970-1995
In total:

69+M records

$\begin{array}{ll}1.4 \mathrm{~B} & \overline{\mathbf{O}} \\ \text { cited } & \end{array}$ references 


\section{Mantenimiento de alta calidad : Riguroso proceso de reevaluación y criterios en Scopus}

- Menos de la mitad de los títulos revisados se seleccionan para la cobertura de Scopus

- El Consejo Asesor de Selección de Contenido (Content Selection Advisory Board - CSAB) es selectivo y estricto en calidad: en total 5.411 fueron revisados (2011-2015) de los que solamente 2.587 (48\%) fueron aceptados en Scopus

\section{Strict Quality \& Ethics Selection Criteria*}

The Scopus title selection criteria - our set of clear and transparent guidelines, in combination with reviews by our independent Content Selection \& Advisory Board ensure the quality of titles indexed meets consistently high standards.

*2016 as sample year

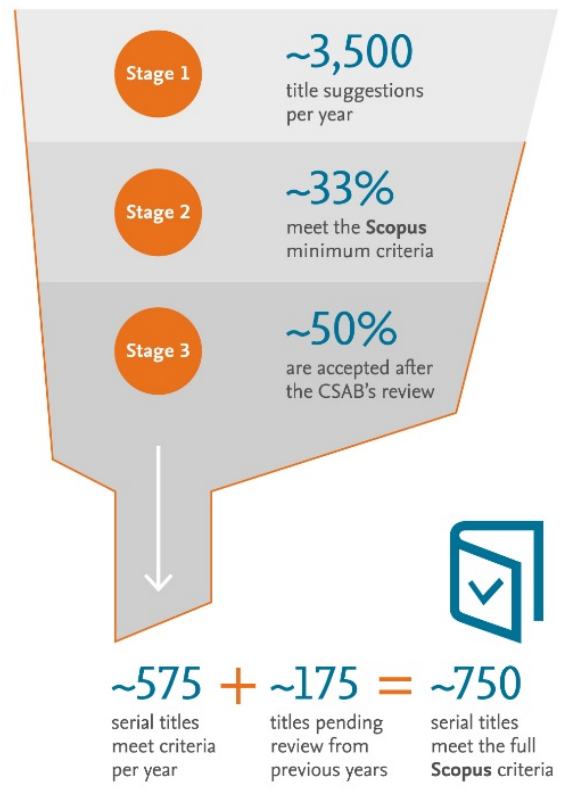

Rigorous Re-evaluation

\section{Process}

In the latest

reevaluation exercise,

303

under-performing

titles were

re-evaluated by the

Content Selection \& Advisory Board

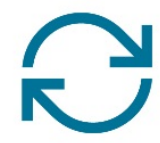

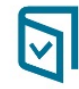

$106(35 \%)$

continue to meet Scopus criteria and coverage will continue

197 (65\%) no longer meet Scopus selection criteria and coverage going forward will be discontinued

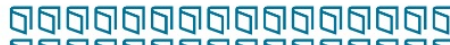
밈ำ

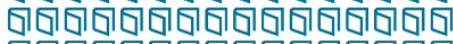
ง ต

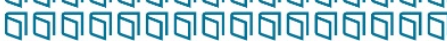

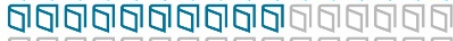
(1)

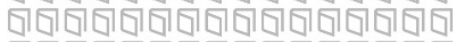
ต ต

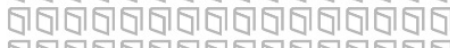

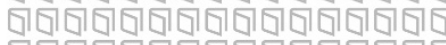

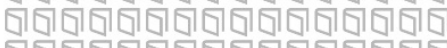
ต

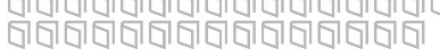




\section{Enfoque estructural: tratamiento de contenido continuo para garantizar contenido de alta calidad}

El tratamiento de la revista completa es esencial y esperada por nuestros clientes y usuarios.

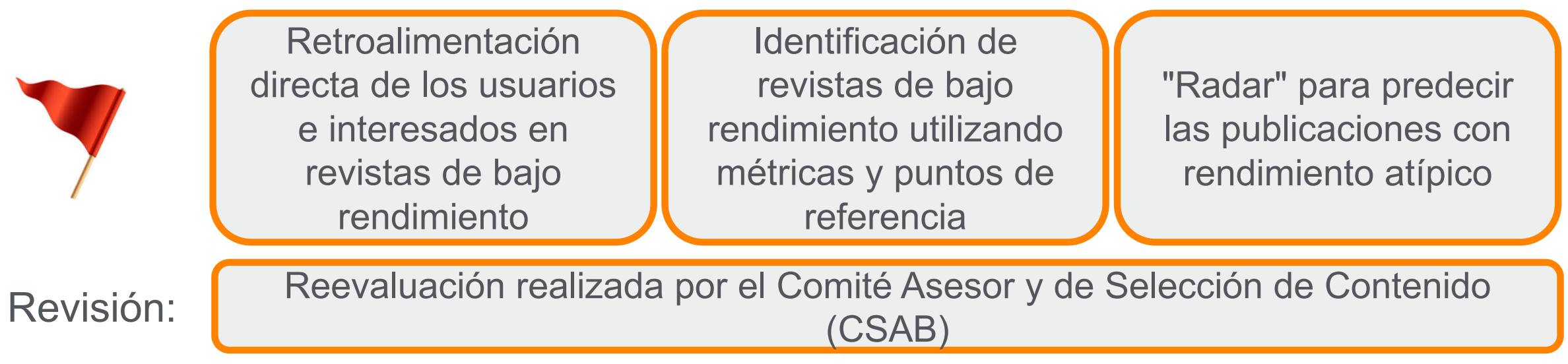

Curación:

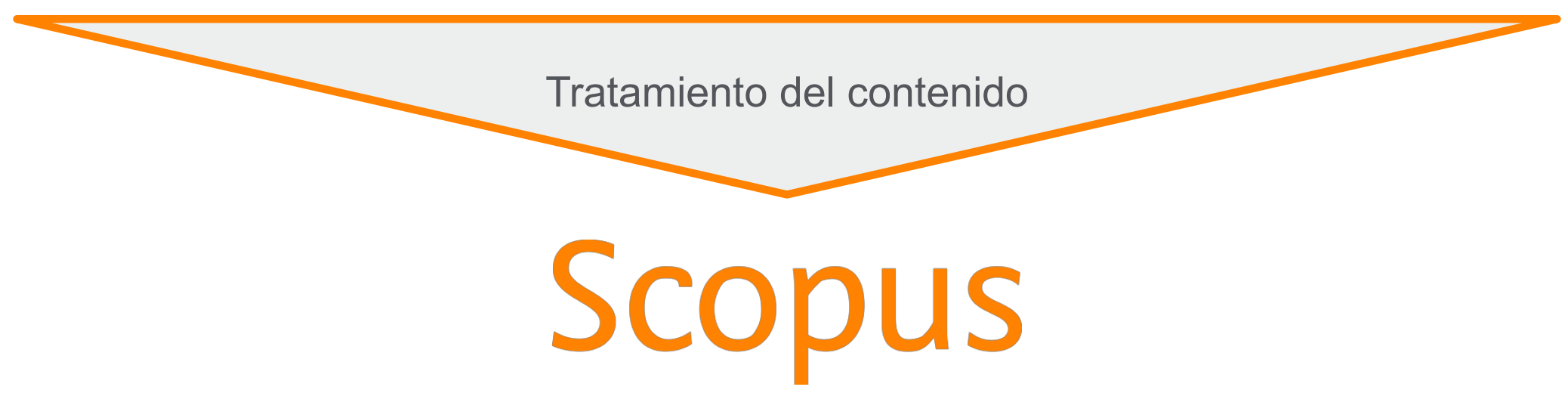




\section{Selección de contenido experto por parte de la Junta de Asesoramiento y Selección de Contenido (CSAB) independiente} Expert Curation

There are
$100,750^{*}$
active
scholarly $\begin{aligned} & \text { Of which } \\ & 43,947^{\star} \\ & \text { are peer- } \\ & \text { reviewed }\end{aligned}$ titles
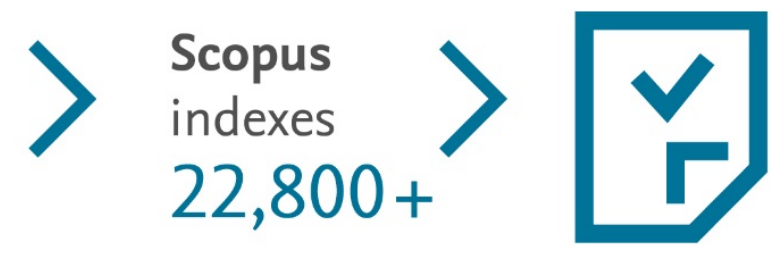

Curated content

> Titles on Scopus are rigorously reviewed and selected by an independent board of subject matter experts to include $52 \%$ of the world's peer-reviewed scholarly literature.

* Source: Ulrich's Web Global Serials Directory, August 1, 2017

- $\quad$ CSAB es una junta independiente de expertos en el tema de todo el mundo..

- Compuesto de 17 Sillas temáticas.

- Los miembros de la junta son elegidos por su experiencia en áreas temáticas específicas; muchos tienen experiencia como Editores (revistas).

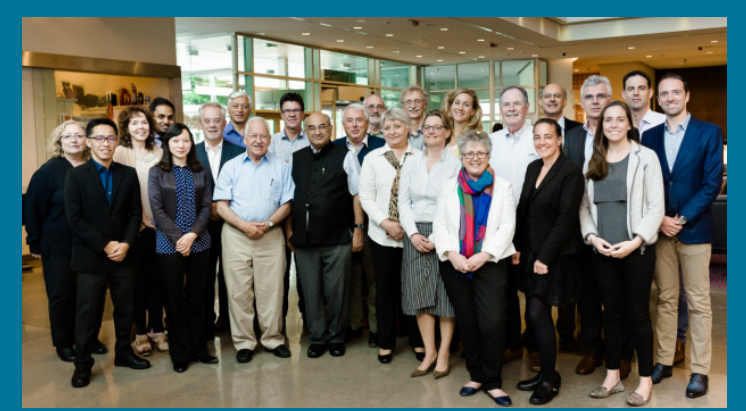




\section{Criterios de selección transparentes de Scopus}

Todos los títulos deben cumplir con todos los criterios mínimos para ser considerados para la revisión de Scopus :

Revisión por
pares

Resúmenes en
inglés

Publicación
periódica
Referencias en alfabeto románico
Declaración Ética

Los títulos elegibles son revisados por la Junta de selección y asesoramiento de contenido según una combinación de 14 criterios de selección cuantitativos y cualitativos:

\begin{tabular}{|c|c|c|c|c|}
\hline $\begin{array}{l}\text { Política de la } \\
\text { revista }\end{array}$ & $\begin{array}{l}\text { Calidad del } \\
\text { contenido }\end{array}$ & Journal Standing & Regularidad & $\begin{array}{l}\text { Disponibilidad en } \\
\text { línea }\end{array}$ \\
\hline $\begin{array}{l}\text { - Concepto / política } \\
\text { editorial convincente } \\
\text { - Tipo de revisión por } \\
\text { pares } \\
\text { - Distribución geográfica } \\
\text { de diversidad de los } \\
\text { editores } \\
\text { - Distribución geográfica } \\
\text { de diversidad de los } \\
\text { autores }\end{array}$ & $\begin{array}{l}\text { - Contribución } \\
\text { académica al campo } \\
\text { - Claridad de los } \\
\text { resúmenes } \\
\text { - Calidad y conformidad } \\
\text { con los objetivos y } \\
\text { alcance establecidos } \\
\text { - Legibilidad de los } \\
\text { artículos }\end{array}$ & $\begin{array}{l}\text { - Cita de los artículos } \\
\text { de revistas en Scopus } \\
\text { - Editor standing }\end{array}$ & $\begin{array}{l}\text { - Cumplimiento de la } \\
\text { periodicidad, sin } \\
\text { retrasos }\end{array}$ & $\begin{array}{l}\text { - Contenido disponible } \\
\text { en línea } \\
\text { - Página de inicio de la } \\
\text { revista en inglés } \\
\text { - Calidad de la página } \\
\text { de inicio }\end{array}$ \\
\hline
\end{tabular}

https://www.elsevier.com/solutions/scopus/content/content-policy-and-selection or titlesuggestion@scopus.com Webinar con más información sobre los criterios de selección de contenido de Scopus: https://blog.scopus.com/webinars 


\section{Cómo acceder a Scopus}




\section{Registro y creación de un perfil personal}

Aunque el acceso a Scopus (www.scopus.com) se realiza mediante IP, podremos sacar el mayor provecho y ahorrar tiempo de investigación creándonos nuestro propio Perfil Personal: https://www.scopus.com/customer/profile/display.uri

Su Perfil Personal le permitirá:

- Guardar búsqueda para posteriores referencias

- Crear alertas de búsqueda

- Crear alertas de cita de artículos que selec

- Guardar listas de artículos seleccionados

- Guardar sus propios grupos de autor

- Pedir correcciones de su Perfil de Autor

$\checkmark$ Introduzca sus datos con su correo institucional

$\checkmark$ Elija una contraseña

$\checkmark$ Acepte el Acuerdo de usuario registrado

$\checkmark$ Haga clic en Register

\section{Register}

Registration is quick and free. It allows you to personalize the Elsevier products to which you have access.

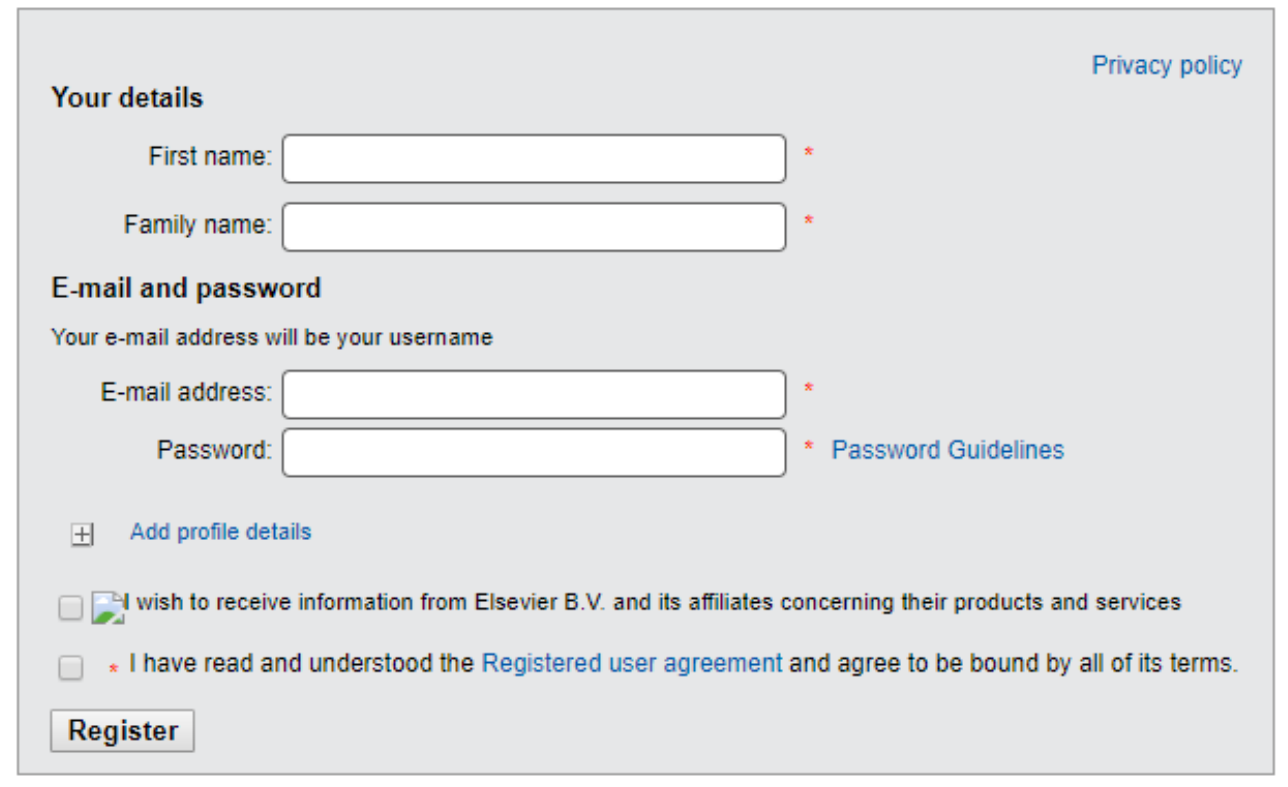




\section{Registro y creación de un perfil personal}

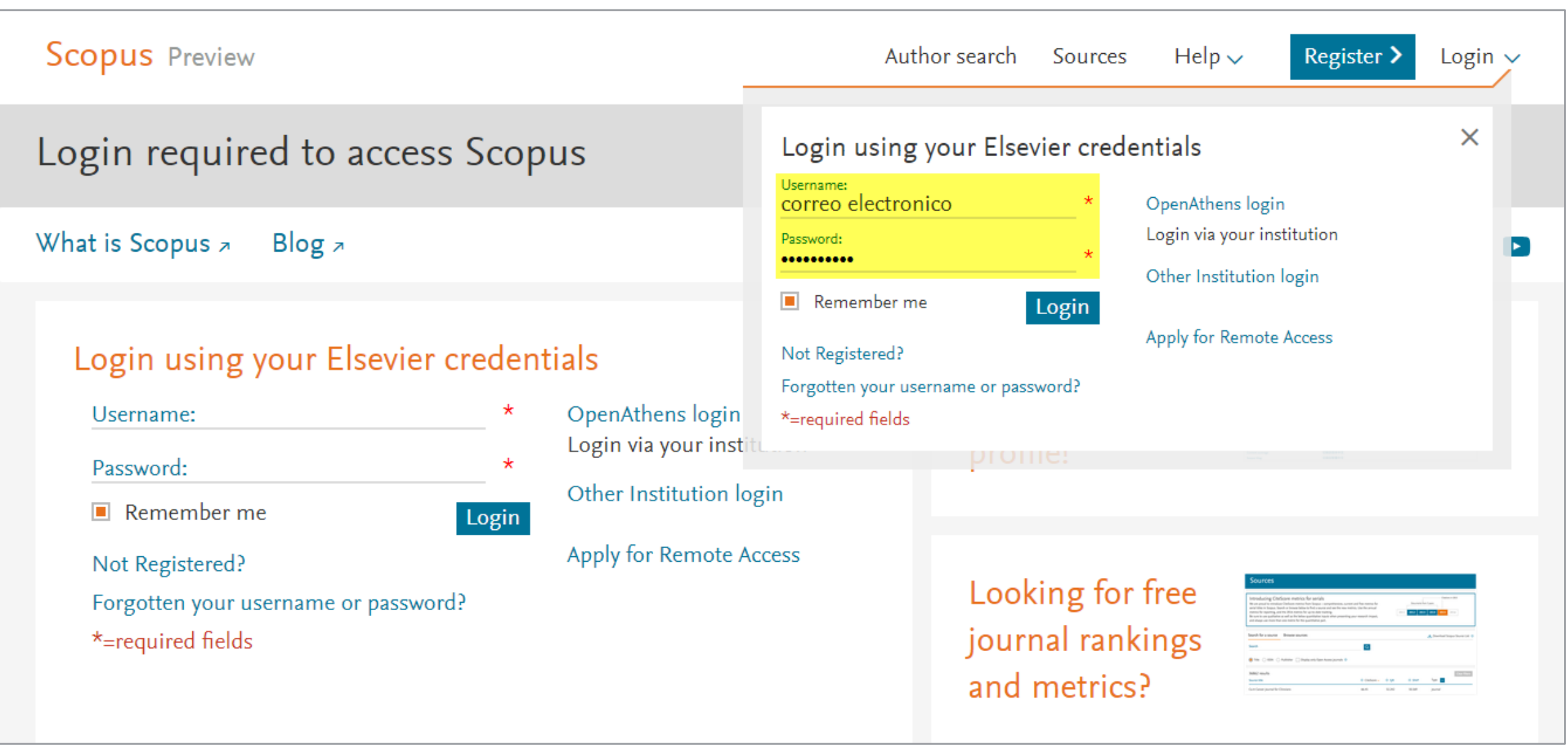

Recibirá un correo electónico con los datos de usuario y la confirmación de la contraseña. En Login, introduzca su nombre de usuario (para nuevas cuentas, será su correo electrónico) y contraseña elegida y haga clic en login. 


\section{Ajustes}

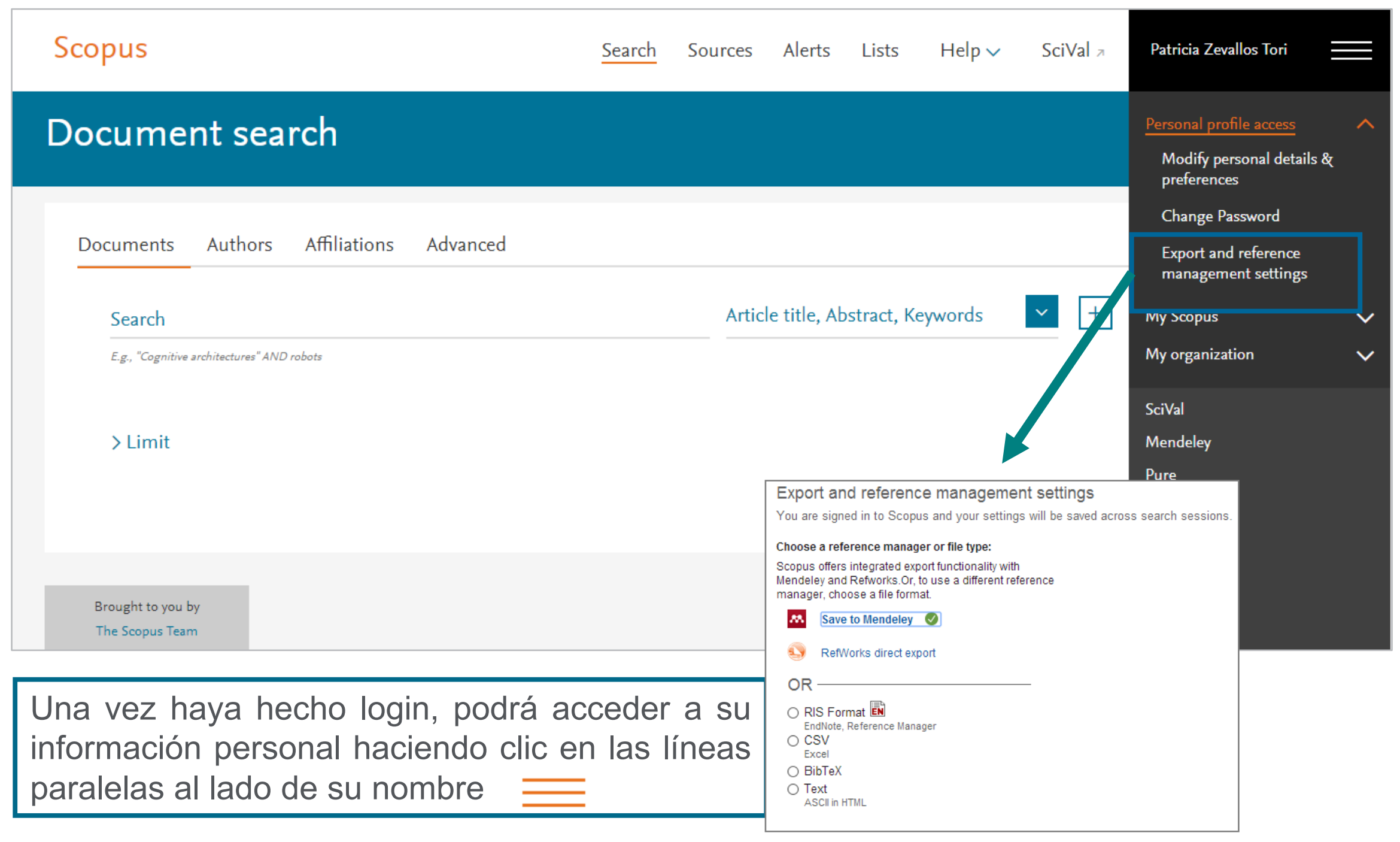




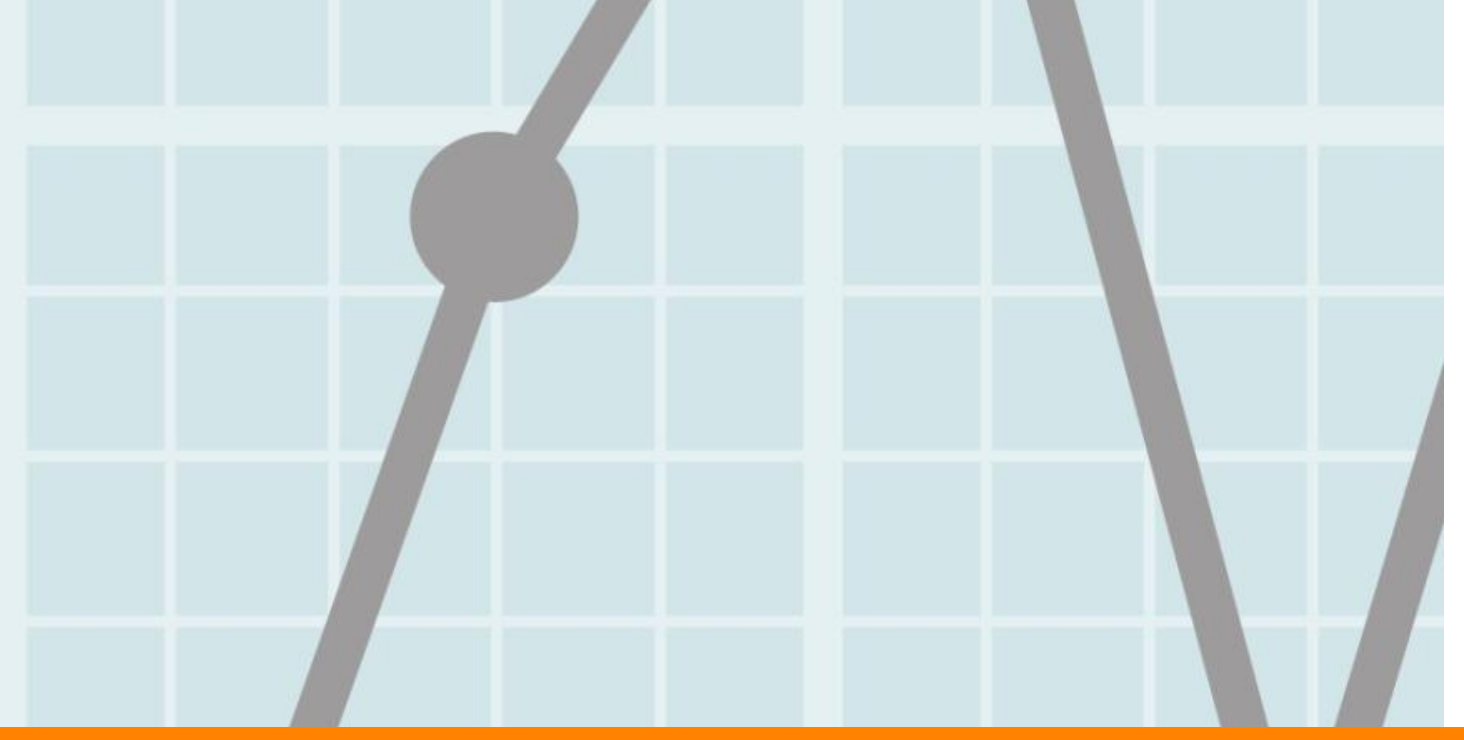

\section{Búsqueda de Documentos y Avanzada}

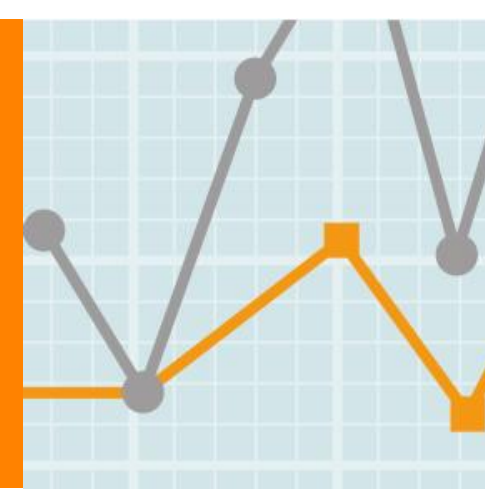




\section{Consejos para mejores resultados en sus búsquedas en Scopus}

- Si busca una palabra en singular, Scopus le dará resultados en singular y plural.

- Para buscar frases: use " " Por ejemplo "heart attack", le dará resultados donde estas dos palabras están adyacentes juntas. También incluirá plurales, por lo que en los resultados también obtendrá heart attacks.

En el campo de búsqueda puede usar comodines :

- Signo de interrogación (?) Representa cualquier carácter individual (por ejemplo, poniendo wom?n encontrará resultados de woman y women)

- Asterisco $\left({ }^{*}\right)$ representa 0 o más caracteres, incluyendo ningún carácter (por ejemplo: trial* tendrá como resultado: trial, trials, trialling, trialled, etc). También puede usar * al principio de la palabra (por ejemplo *estrogen encontrará oestrogen como también estrogen)

Sólo se puede utilizar un comodín a la vez. 
Operadores Booleanos: AND, OR y AND NOT

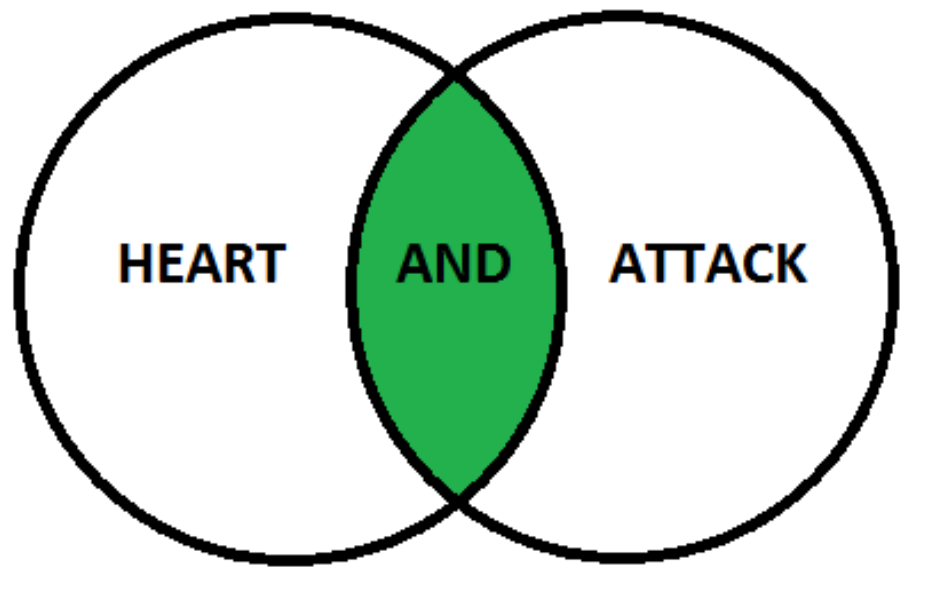

OR: Incluye los resultados de HEART o de ATTACK

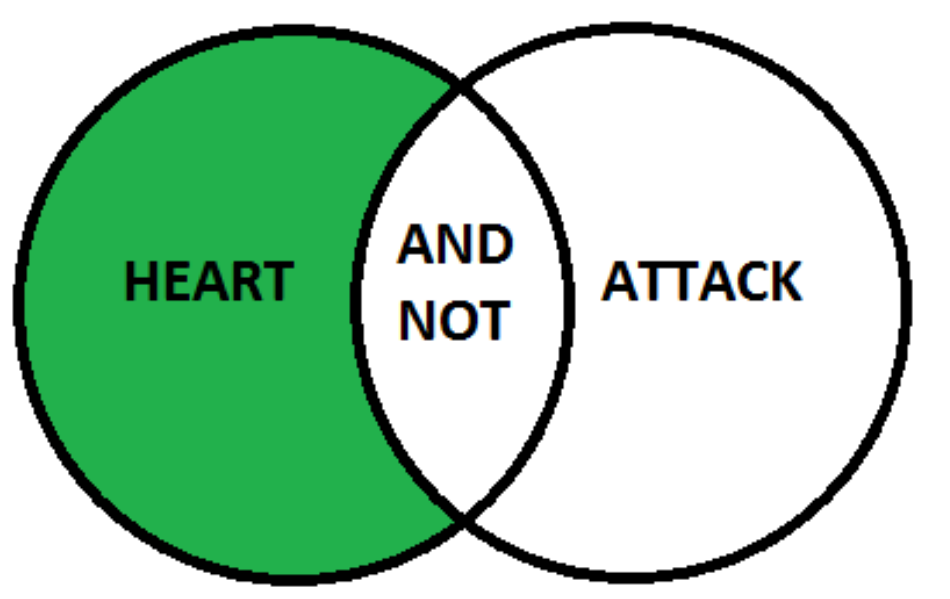

AND: Incluye todos los resultados de HEART y ATTACK

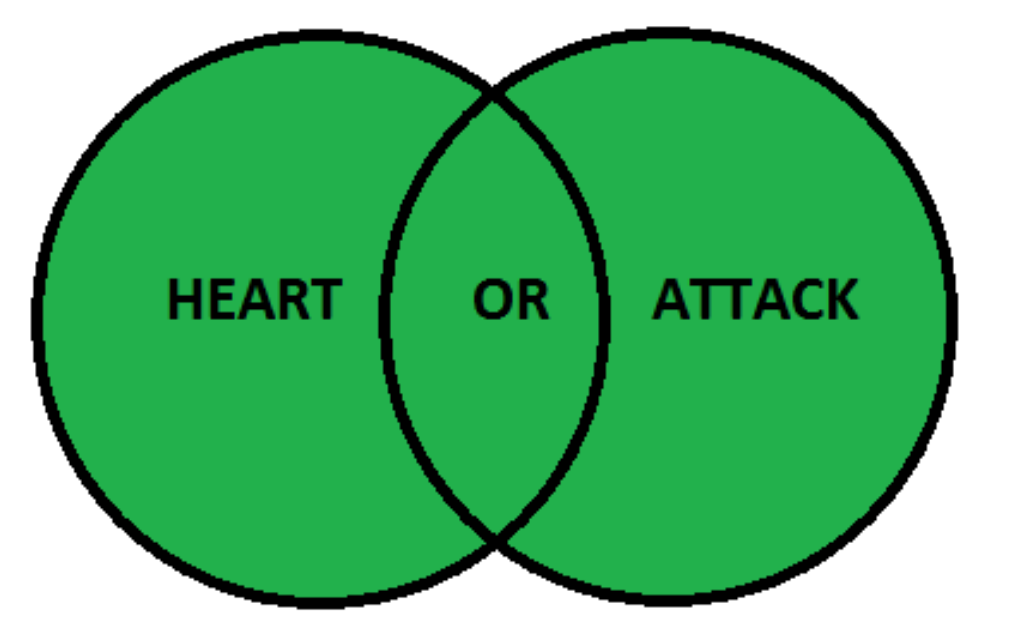

AND NOT: Sólo los resultados de HEART que no incluyan ATTACK 


\section{Operadores de Proximidad: PRE/}

PRE/n (precedido por). El primer término precede al segundo en un número de palabras que va desde 0 hasta el número indicado como máximo. Por ejemplo, en: policystic PRE/4 kidney, el número de palabras máximo es 4 . Es decir, el sistema devolverá referencias de documentos donde el término «policystic» preceda a «kidney» en una distancia no mayor de 4 palabras.

\section{0 document results}

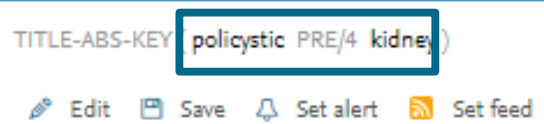

Search within results...

Refine results

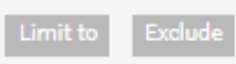

Document type

Language

$\square$ English

$\square$ Spanish

$\square$ French

$\square$ Polish

$\square$ Portuguese
叫 Analyze search results

Show all abstracts Sort on: Cited by (highest)

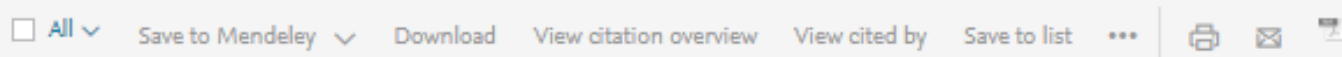

\begin{tabular}{|c|c|c|c|c|c|}
\hline & Document title & Authors & Year & Source & Cited by \\
\hline$\square 1$ & Ion channels-related diseases & $\begin{array}{l}\text { Dworakowska, B., } \\
\text { Dołowy, K. }\end{array}$ & 2000 & $\begin{array}{l}\text { Acta Biochimica Polonica } \\
47(3) \text {, pp. } 685-703\end{array}$ & 37 \\
\hline
\end{tabular}

View abstract $\checkmark$ OCSic eriaces $\square$ Full Text $\square$ Related documents

Place of laparoscopic cysts decortication (LCD) in the treatment of autosomal dominant policystic kidney disease

(AD PKD) I [Place de la résection laparoscopique des kystes

rénaux pour polykystose rénale autosomique dominante

Fryczkowski, M.

Huk, J., Sitko-

Saucha, A., Kupilas,

2007 Progres en Urologie $17(7)$, pp. $1324-1327$ symptomatique]

View abstract $\checkmark$ Ocsic eniaces $\square$ Full Text $\quad$ Related documents 


\section{Operadores de Proximidad: WI}

W/n "within". Cuando las palabras tiene una distancia de n lugares entre sí, no importa el orden. Por ejemplo, en: chemical W/3 modification, el número de palabras máximo es 3. Es decir, el sistema devolverá referencias de documentos donde el término «chemical» tiene una distancia de 3 palabras entre «modification» sin importar el orden.

\section{1,506 document results}

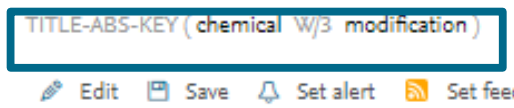

Search within results.

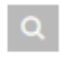

Refine results

\section{Limit to Exdude}

Document type

Language

$\square$ English

$\square$ Chinese

$\square$ Russian

$\square$ Japanese

$\square$ German

View more

Year
메 Analyze search results

Show all abstracts Sort on: Cited by (highest)

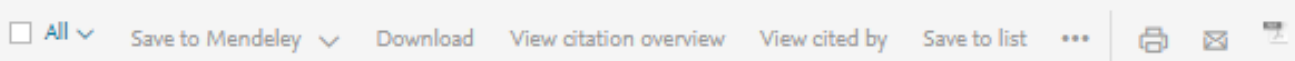

\begin{tabular}{|c|c|c|c|c|c|}
\hline & Document title & Authors & Year & Source & Cited by \\
\hline$\square 1$ & Graphene-based composite materials & $\begin{array}{l}\text { Stankovich, S., Dikin, D.A., } \\
\text { Dommett, G.H.B., (...). } \\
\text { Nguyen, S.T., Ruoff, R.S. }\end{array}$ & 2006 & $\begin{array}{l}\text { Nature } \\
442(7100) \text {, pp. } 282-286\end{array}$ & 7350 \\
\hline
\end{tabular}

View abstract $\checkmark$ OCsceriaces $\square$ Full Text Related documents

4 $\square 2$ Mass spectrometric sequencing of proteins from silver- Shevchenko, A., Wilm, M., stained polyacrylamide gels

Vorm, O., Mann, M.

1996 Analytical Chemistry 68(5), Pp. 850-858

6776

View abstract $\vee$ OCsic eriacos

Related documents

$\square 3$ Titanium dioxide nanomaterials: Synthesis, properties, Chen, X., Mao, S.S. modifications and applications

2007 Chemical Reviews 107(7), pp. 2891-2959 


\section{Búsqueda de documentos}

\section{Document search}

Documents Authors Affiliations Advanced
Search

Eg, "Cognitive architectures" AND robots

$\checkmark$ Limit

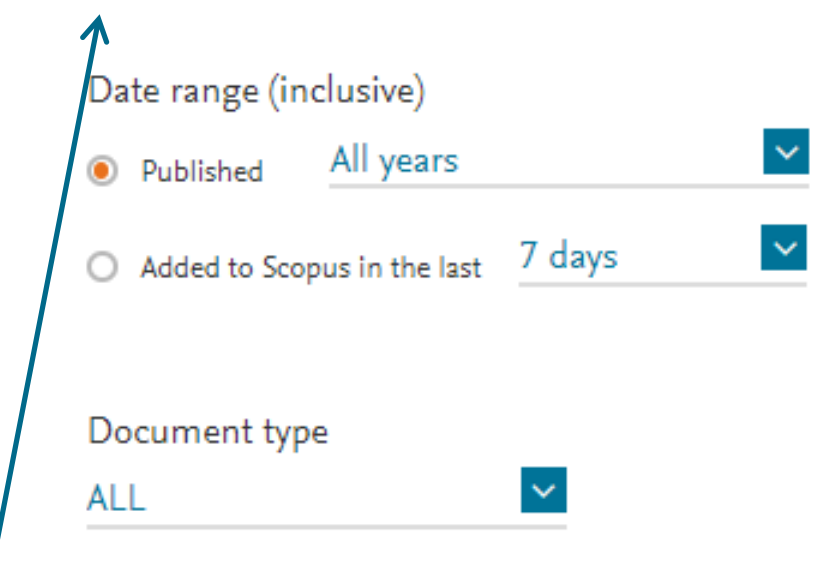

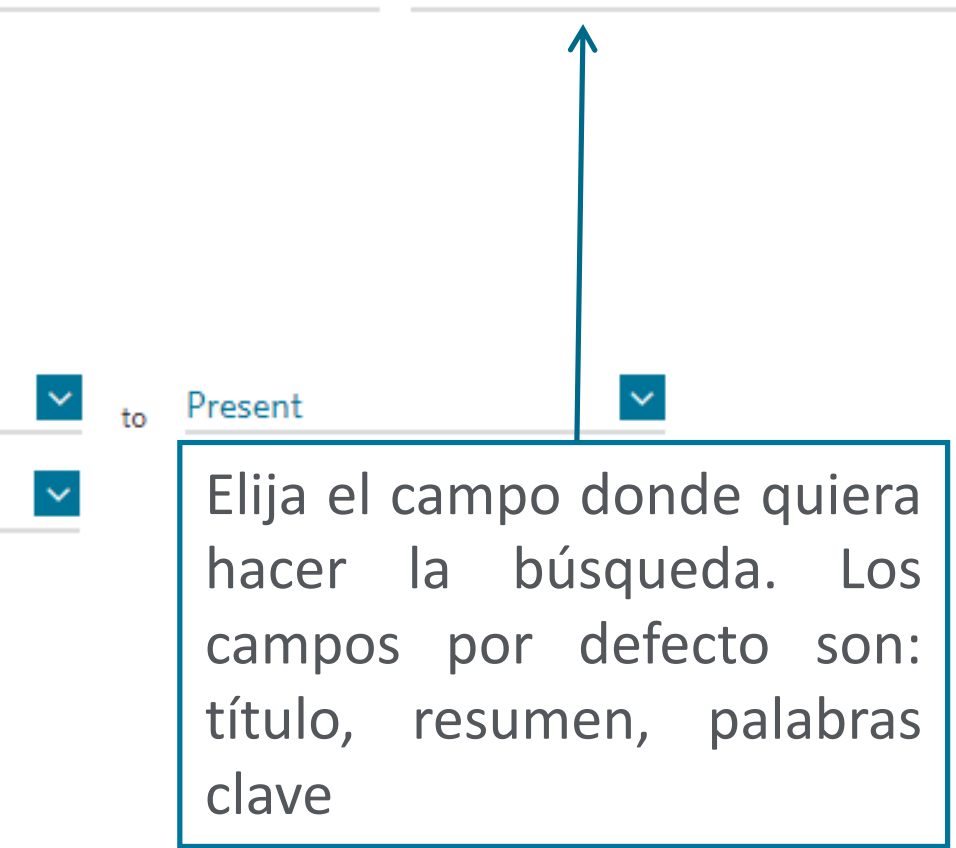

Reset form
Limite su búsqueda por año de publicación o tipo de contenido 


\section{Refine sus resultados}

\begin{tabular}{|c|c|}
\hline Search wathin results. & a \\
\hline \multicolumn{2}{|l|}{ Refine results } \\
\hline \multicolumn{2}{|l|}{ Umit to Eridude } \\
\hline Year & $\wedge$ \\
\hline$\square 2017$ & $(1,164)>$ \\
\hline$\square 2016$ & $(1,830)>$ \\
\hline$\square$ 2015 & (53) $>$ \\
\hline$\square 2014$ & (29) $>$ \\
\hline$\square 2013$ & (3) $>$ \\
\hline \multicolumn{2}{|l|}{ View more } \\
\hline Author name & $\checkmark$ \\
\hline Subject area & $\checkmark$ \\
\hline Document type & $\checkmark$ \\
\hline Source title & $\checkmark$ \\
\hline Keyword & $\checkmark$ \\
\hline Affliation & $\checkmark$ \\
\hline Country/territory & $\checkmark$ \\
\hline Source type & $\vee$ \\
\hline Language & $\checkmark$ \\
\hline Limit to Erdude & \\
\hline & $\rightarrow$ Export refine \\
\hline
\end{tabular}

Limite o excluya los resultados basándose en listas de títulos de fuentes, Nombres de Autor, Año, Tipo de Documento, Área temática, Palabras clave, Idioma, Tipo de Publicación o Afiliación Y/O Buscar en los resultados (Search within results) 


\section{Análisis de resultados: Analyze search results}

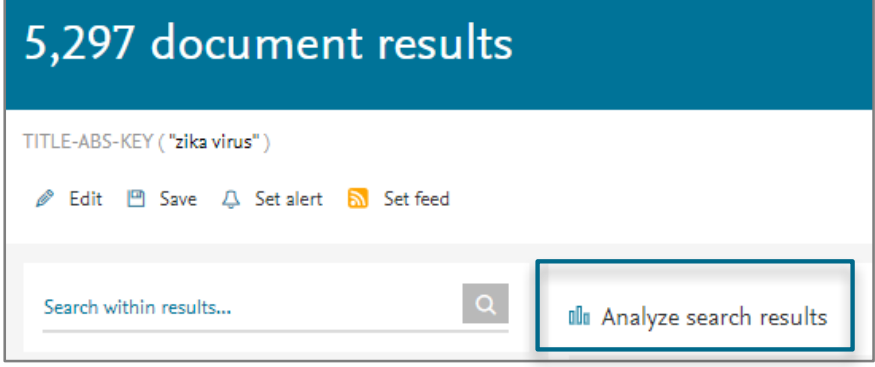

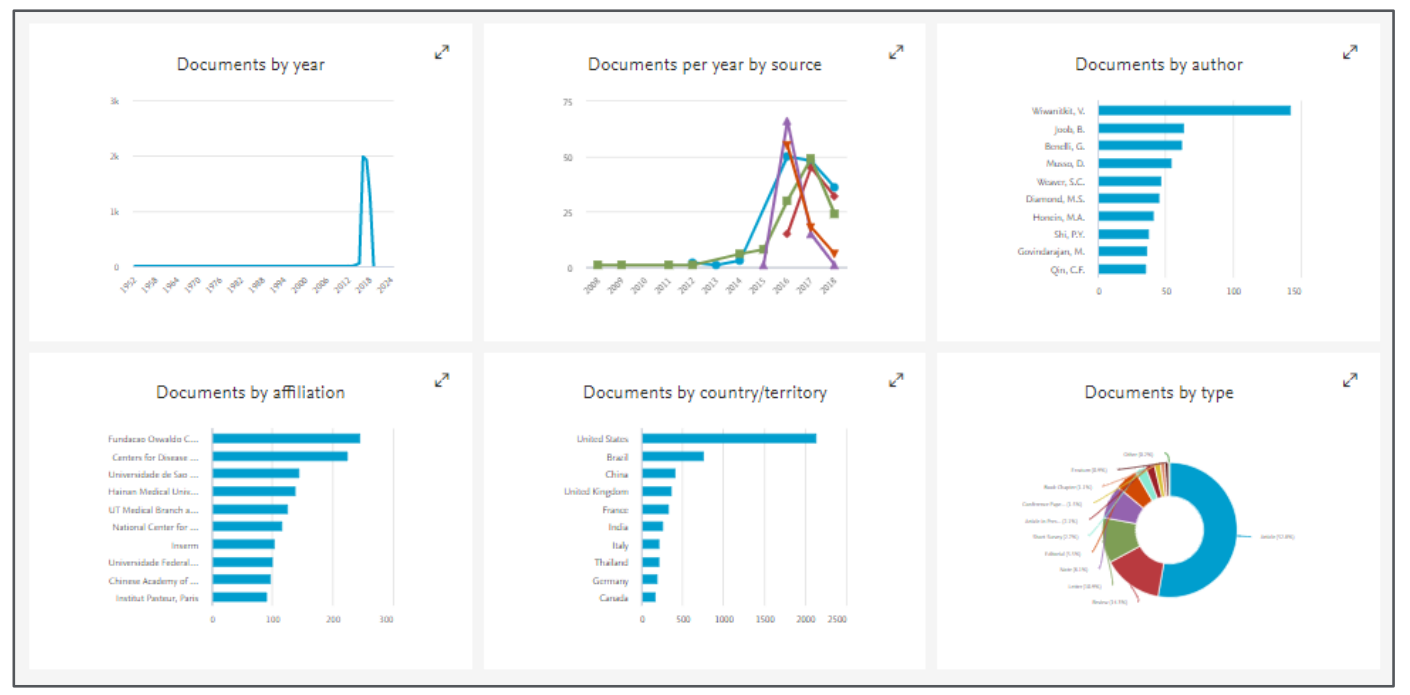

\section{Analyze search results}

\begin{tabular}{|c|c|}
\hline \multicolumn{2}{|l|}{$\begin{array}{l}\text { <Back to results } \\
\text { TITLE-ABS-KEY ("zika virus") }\end{array}$} \\
\hline 5,297 document results & \\
\hline Subject area $\downarrow$ & Documents $\downarrow$ \\
\hline Medicine & $3640^{\wedge}$ \\
\hline Immunology and Microbiology & 1253 \\
\hline $\begin{array}{l}\text { Biochemistry, Genetics and Molecular } \\
\text { Biology }\end{array}$ & 907 \\
\hline $\begin{array}{l}\text { Pharmacology, Toxicology and } \\
\text { Pharmaceutics }\end{array}$ & 318 \\
\hline Agricultural and Biological Sciences & 302 \\
\hline Multidisciplinary & 254 \\
\hline Environmental Science & 198 \\
\hline Neuroscience & 184 \\
\hline
\end{tabular}

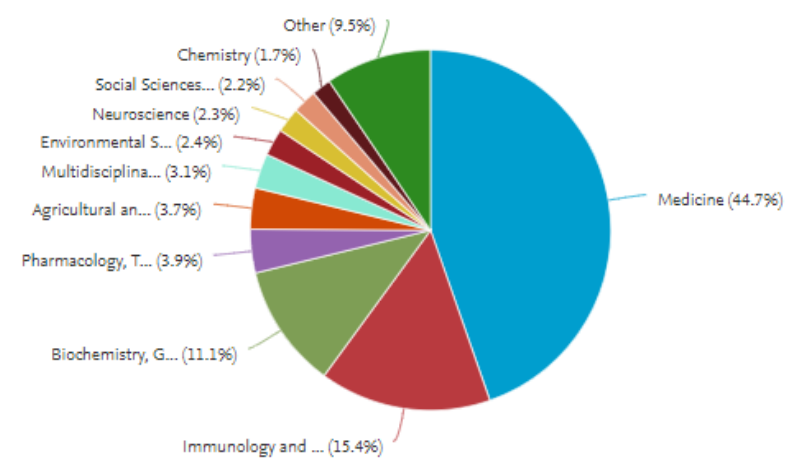




\section{Funcionalidades de Scopus}

\section{5,297 document result Guarde su búsqueda o cree

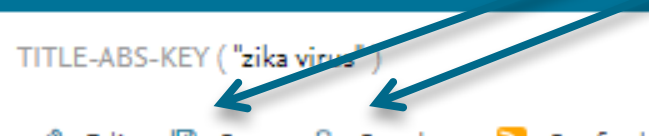 \\ Edit $\square$ Save $\Delta$ Set alert $\Delta$ Set feed una alerta de búsqueda \\ búsqueda}

Search within results...

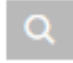

Refine results

\section{Limit to Exclude}

Year

$\square 2019$

$\square 2018$

$\square 2017$

$\square 2016$

$\square 2015$

View more

Access type (1) uln Analyze search results

$\square$ All

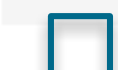




\section{Guardar listas de documentos}

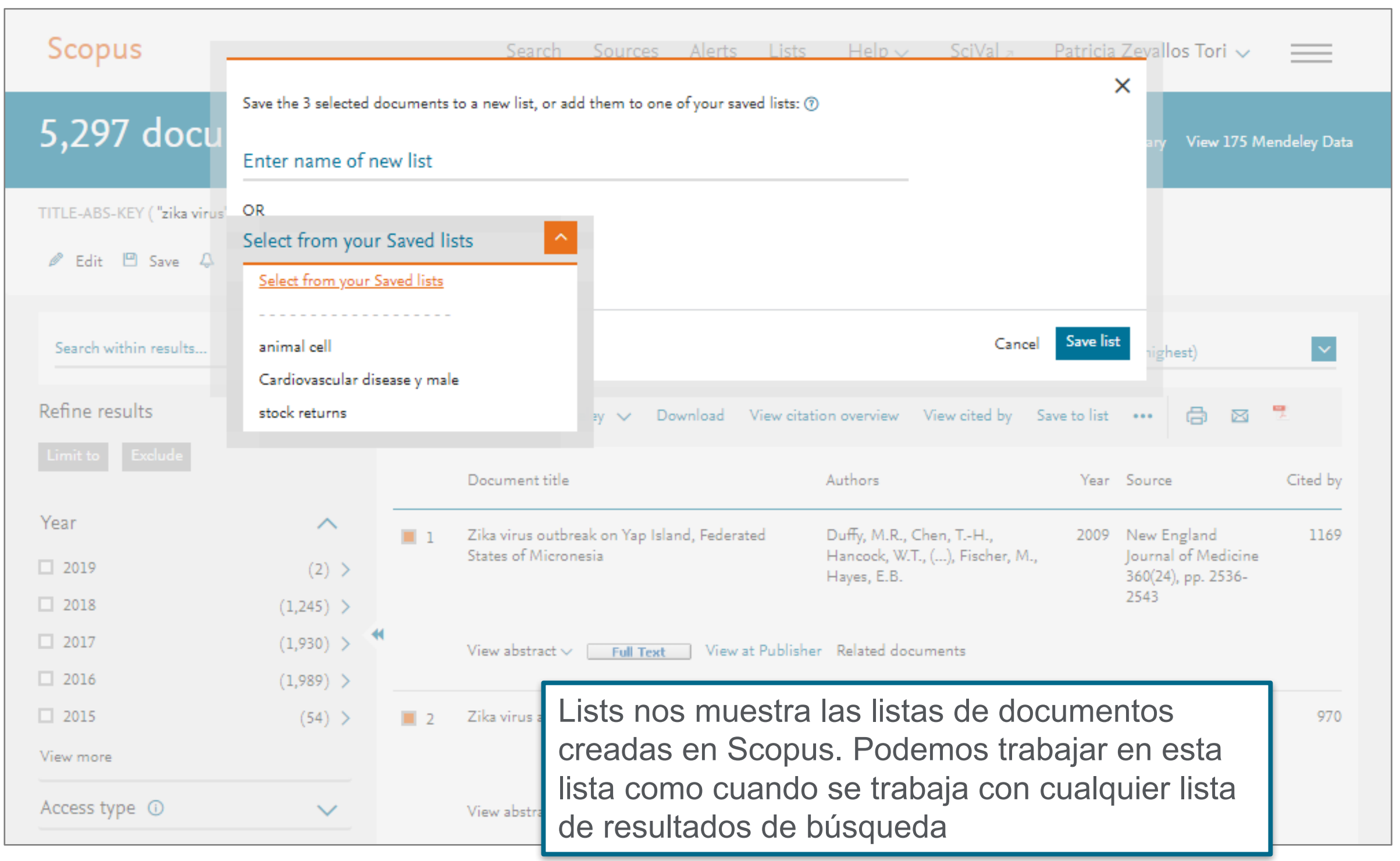




\section{Exportar}

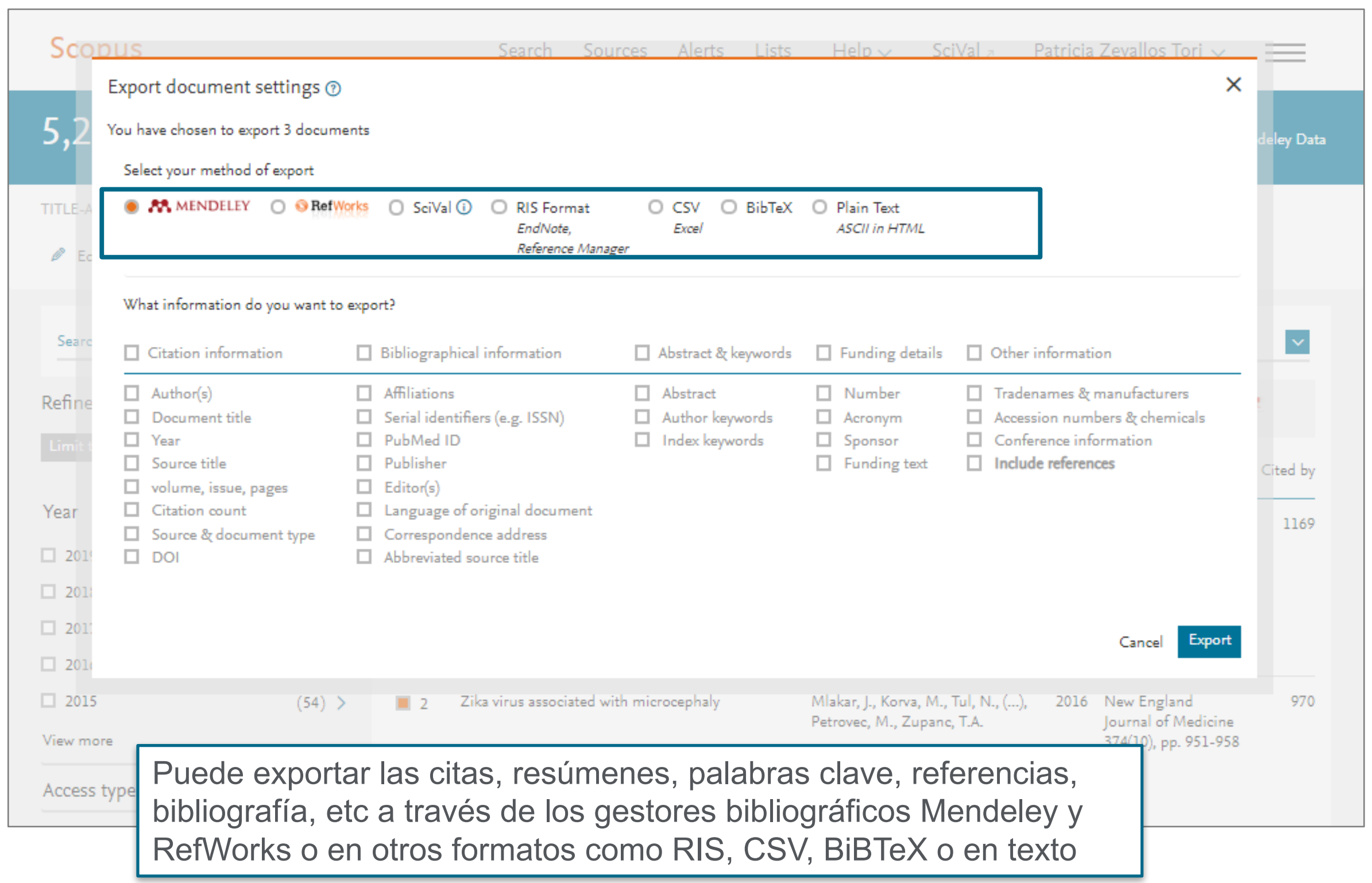




\section{Imprimir, email y crear bibliografía}

\section{5,297 document results}

TITLE-ABS-KEY ( "zika virus")
Edit
回ave
$\Delta$ Set alert
Set feed

Search within results...

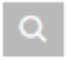

口iln Analyze search results

Show all abstracts Sort on:

Cited by (highest)

\section{Refine results}

$\square$ All $\vee \quad$ Save to Mendeley $\vee \quad$ Download

View citation overview

View cited by Save to list

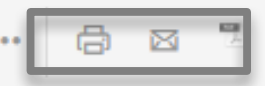

\section{Limit to Exclude}

Print, email, save as PDF, or create a bibliography

< Back

Print Email Save as PDF Bibliography: QuikBib

What information do you want to print?

口 Citation information

$\square$ Bibliographical information

$\square$ Abstract and Keywords

$\square$ Funding Details

$\square$ Other information

$\begin{array}{ll}\square \text { Author(s) } & \square \text { Affliations } \\ \square \text { Document title } & \square \text { Serial identifiers (e.g. ISSN) } \\ \square \text { Year } & \square \text { DOI } \\ \square \text { Source title } & \square \text { PubMed ID } \\ \square \text { Volume, issue, pages } & \square \text { Publisher } \\ \square \text { Citation count } & \square \text { Editor(s) } \\ \square \text { Source \& document type } & \square \text { Language of Original Document } \\ \square \text { EID } & \square \text { Correspondence Address } \\ \square \text { Access Type } & \square \text { Abbreviated Source Title }\end{array}$

\section{$\square$ Abstract}

$\square$ Number

$\square$ Tradenames and Manufacturers
$\square$ Accession numbers and Chemica

$\square$ Author Keywords

$\square$ Acronym

$\square$ Index Keywords

$\square$ Sponsor

$\square$ Conference information

$\square$ Source title

$\square$ PubMed ID

$\square$ Funding Text

$\square$ References

$\square$ Access Type

$\square$ Abrespondence Address 


\section{Ver las referencias y las citas para unos documentos seleccionados}

\section{5,297 document results}

TITLE-ABS-KEY ( "zika virus")

Edit $\square$ Save $\Delta$ Set alert $ه$ Set feed

Search within results...

Refine results

\section{Limit to Exclude}

Year

$\square 2019$

$\square 2018$

$\square 2017$

$\square 2016$

$\square 2015$

View more
Q

⿰口口o Analyze search results

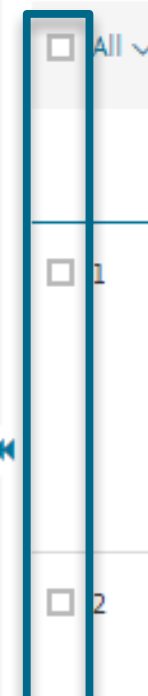

Document title
Show all abstracts Sort on: Cited by (highest)

$\checkmark$
View citation overview

View cited by

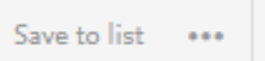

吕 छ

Authors

Year Source

Zika virus outbreak on Yap Island, Federated

Duffy, M.R., Chen, T.-H.,

Hancock, W.T., (...), Fischer, M., Hayes, E.B.

2009 New England Journal of Medicine $360(24)$, pp. $2536-$ 2543

View abstract $\checkmark \quad$ Full Text View at Publisher Related documents

Zika virus associated with microcephaly

Mlakar, J., Korva, M., Tul, N., (...), Petrovec, M., Zupanc, T.A.

2016 New England Journal of Medicine 374(10), pp. $951-958$ 


\section{Citation Overview: ¿Qué es? Posibles aplicaciones}

Cálculos en tiempo real de la información general de las citas:

Selección de artículos o todos los artículos por un Todos los artículos publicados por una revista autor específico específica para un año dado

Todos los recuentos de citas y enlaces a artículos Fácil de imprimir y exportar se visualizan en la misma pantalla

\section{Posibles aplicaciones}

- Solicitud de subvención para los grupos de investigación

- Contratación

- Evaluación de una universidad, departamento o producción científica de un grupo de investigación

- Elección de un tutor para un programa de maestría o doctorado

- Puede ser agregado al CV o página web del autor 


\section{Visualización de citas: Citation overview}

\section{Citation overview}

< Back to document results

马] Export 骨 Print

This is an overview of citations for the documents you've selected.

Document $h$-index: 3 View $h$-graph ()

3 cited documents + save to list

Date range: 2014

V to 2018 V

$\square$ Exclude self citations of all authors

Exclude citations from books

Update

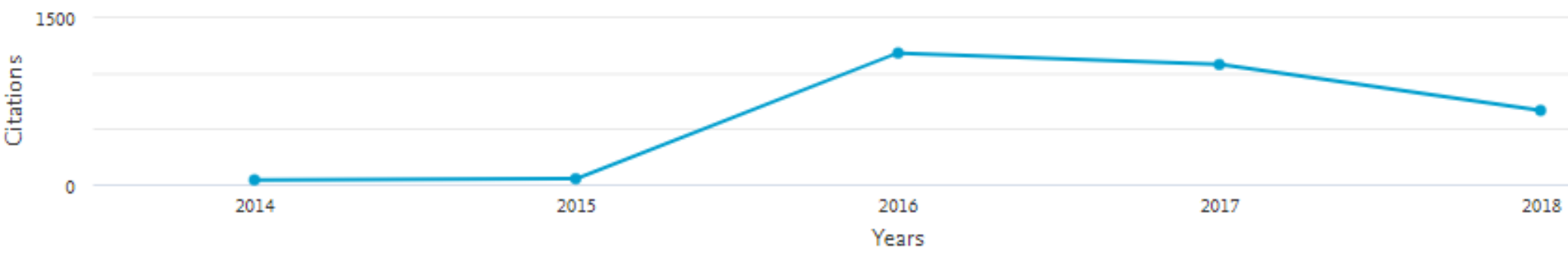

Sort on: Date (newest)

\begin{tabular}{|c|c|c|c|c|c|c|c|c|c|c|c|}
\hline & Documents & Citations & $<2014$ & 2014 & 2015 & 2016 & 2017 & 2018 & Subtotal & $>2018$ & Total \\
\hline & & Total & 46 & 39 & 49 & 1181 & 1077 & 664 & 3010 & 0 & 3056 \\
\hline$\square 1$ & Zika virus associated with microcephaly & 2016 & & & 1 & 396 & 361 & 212 & 970 & & 970 \\
\hline$\square 2$ & Zika virus outbresk on Yap Island, Foderated States of Miero... & 2009 & 27 & 27 & 29 & 454 & 389 & 243 & 1142 & & 1169 \\
\hline$\square 3$ & Zika Virus (1). Isolations and sarological specificity & 1952 & 19 & 12 & 19 & 331 & 327 & 209 & 898 & & 917 \\
\hline
\end{tabular}




\section{Búsqueda Avanzada}

\section{Advanced search}

Compare sources >

Documents Authors Affiliation Advanced

Search tips (2)

Enter query string

(ALL("juvenile dermatomyositis") AND ALL(treatment)) AND ( LIMIT-TO (PUBYEAR,2016) OR LIMIT-

TO (PUBYEAR,2015) OR LIMIT-TO (PUBYEAR,2013) OR LIMIT-TO (PUBYEAR,2010) OR LIMIT-TO(

PUBYEAR,2007) OR LIMIT-TO (PUBYEAR,2004) OR LIMIT-TO (PUBYEAR,1993)) AND (LIMIT-TO (

LANGUAGE,"English ") OR LIMIT-TO ( LANGUAGE,"Spanish ") OR LIMIT-TO (

LANGUAGE,"Portuguese ") OR LIMIT-TO ( LANGUAGE,"Italian ") OR LIMIT-TO ( LANGUAGE,"Korean

") OR EXCLUDE ( LANGUAGE,"French ") OR EXCLUDE ( LANGUAGE,"German ") OR EXCLUDE (

LANGUAGE,"Polish ") OR EXCLUDE ( LANGUAGE,"Turkish " ))

\section{Outline query Add Author name/Affiliation Clear form Search Q}

Operators

$\begin{array}{ll}\text { AND } & \text { (1) } \\ \text { OR } & \text { (1) } \\ \text { AND NOT } & \text { (1) } \\ \text { PRE/ } & \text { (1) } \\ \text { W] } & \text { (1) }\end{array}$

\begin{tabular}{|c|c|c|c|c|}
\hline Code: & AFFILCITY & \multicolumn{3}{|l|}{ Field codes $(1)$} \\
\hline Name: & Affiliation City & ABS & (1) & $\Delta$ \\
\hline Description: & The city portion of an author address. & 7 & (1) & \\
\hline \multirow[t]{6}{*}{ Example: } & Entering AFFILCITY(beijing) will return documents where "beijing" is the city in the author affiliation & AFFIL & & \\
\hline & Beijing Engineering Software Technology Co., Ltd., Beijing 100081, China & AFFILCITY & (1) & \\
\hline & & AFFILCOUNTRY & (1) & \\
\hline & & AFFILORG & (1) & \\
\hline & & ALL & (1) & \\
\hline & & ARTNUM & (1) & \\
\hline
\end{tabular}




\section{Búsqueda avanzada}

Ir a la parte inferior de Scopus.com: content coverage

En la página de info de Scopus: Download the Scopus source list; y entrar en la pestaña de excel ASJC code list

\begin{tabular}{l|l|}
\hline Code & Description \\
\hline 1000 & Multidisciplinary \\
\hline & Multidisciplinary \\
\hline 1100 & General Agricultural and Biological Sciences \\
\hline 1101 & Agricultural and Biological Sciences (miscellaneous) \\
\hline 1102 & Agronomy and Crop Science \\
\hline 1103 & Animal Science and Zoology \\
\hline 1104 & Aquatic Science \\
\hline 1105 & Ecology, Evolution, Behavior and Systematics \\
\hline 1106 & Food Science \\
\hline 1107 & Forestry \\
\hline 1108 & Horticulture \\
\hline 1109 & Insect Science \\
\hline 1110 & Plant Science \\
\hline 1111 & Soil Science \\
\hline & ^rte and Lumanitiac \\
\hline
\end{tabular}

\section{Documents Authors Affiliations Advanced}

Enter query string

subjterms(1311)

ALL("heart attack") AND AUTHOR-NAME(smith)

TITLE-ABS-KEY("somatic complaint wom?n) AND PUBYEAR AFT 1993

SRCTITLE('field ornith*) AND VOLUME(75) AND ISSUE(I) AND PAGES(53-66)
Busque "subjterms (x)" si usted está en busca de contenido de un campo específico 


\section{Búsqueda Avanzada: Libros}

Hay tres campos de búsqueda:

\section{Advanced search}

Documents

Authors Affiliations

Advanced

Enter query string

DOCTYPEO

Outline query Add Author name / Affliation

Search Q

Code: $\quad$ DOCTYPE

Name: $\quad$ DOCTYPE $(\infty)$

Description: $\quad$ Entering DOCTYPE(ar) will return documents classified as articles.

Artide-ar / Article in Press-ip / Abstract Report-ab / Book-bk / Book Chapter-ch / Business Article-bz / Conference Paper-cp / Conference Review-cr / Editorial-ed / Erratum-er / Letter-le/ Note-no / Press Conference Paper-cp / Conference Review-cr / Editorial-
Release-pr / Report-rp / Review-re / Short Survey-sh
- Búsqueda por tipo de documento: Busque por DOCTYPE(bk) en la búsqueda avanzada [para items relacionados con un libro completo]

- Busque por DOCTYPE(ch) en la búsqueda avanzada [para ítems que sean capítulos de libros]

- Busque por tipo de fuente: Busque por SRCTYPE(b) en la búsqueda avanzada [para todos los ítems que pertenezcan a el tipo de fuente libro] el proyecto (finaliza en 2015) y a continuación se añadiran 10.000 libros nuevos anualmente. 


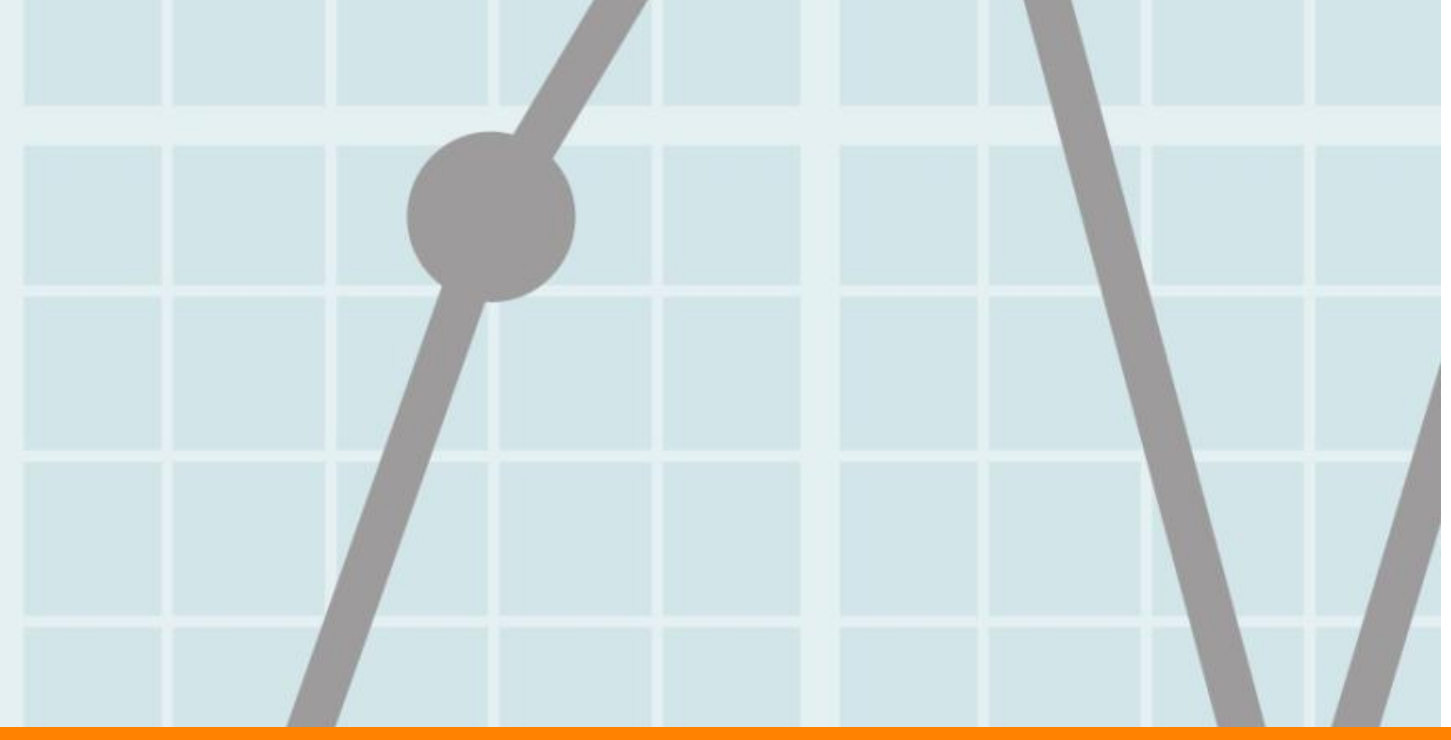

\section{Perfiles en Scopus}




\section{Scopus: la fuente principal de perfiles}

- Incluyendo perfiles de autor y de afiliación, Scopus ofrece una visión completa sobre el mundo de la investigación.

- Scopus incluye 13,1M Perfiles de Autor y 10,9M Perfiles de Afiliación*.

- Scopus es la única base de datos que implementa la desambiguación de autor algorítmica y sistemática con gran precisión para crear y mantener perfiles precisos y completos.

- Los autores pueden solicitar cambios usando el Author Feedback Wizard.

SCOPUS CUSTOMER TESTIMONIAL

44 The use of Scopus has boosted my research activities because I easily find information and authors in my research area. I am also informed in real time about work being done in my research areas.

- - Faculty, Educational Institution, Cameroon 


\section{Scopus: la fuente principal de perfiles}

\section{Generación de perfil de autor}

Scopus es la única base de datos que implementa la desambiguación algorítmica y sistemática del autor.

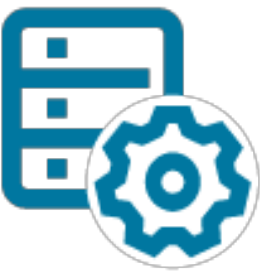

El procesamiento de datos algorítmicos más potente de la industria agrupa los trabajos en el perfil de un individuo con un alto grado de precisión basado en la coincidencia de nombre, correo electrónico, afiliación, área temática, citas, coautores, etc.

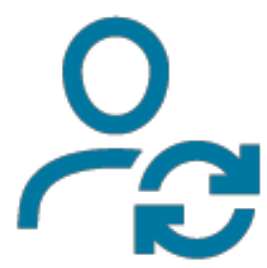

El Author Feedback está disponible para los cambios del perfil del autor a ser solicitados debido a la complejidad de desambiguación, tales como nombres comunes, cambios de nombre, metadatos incompleta de las editoriales, etc. Scopus realiza los máximos esfuerzos para actualizar y mantener descripciones precisas y completas.

\section{El modelo de datos Scopus}

Los datos que entra en Scopus sigue el modelo que los artículos son escrito por autores que están afiliados a instituciones

Este modelo de datos relacionales significa que Scopus puede decirle quién está investigando qué en la literatura mundial y dónde lo están haciendo con mayor precisión que cualquier otra persona.

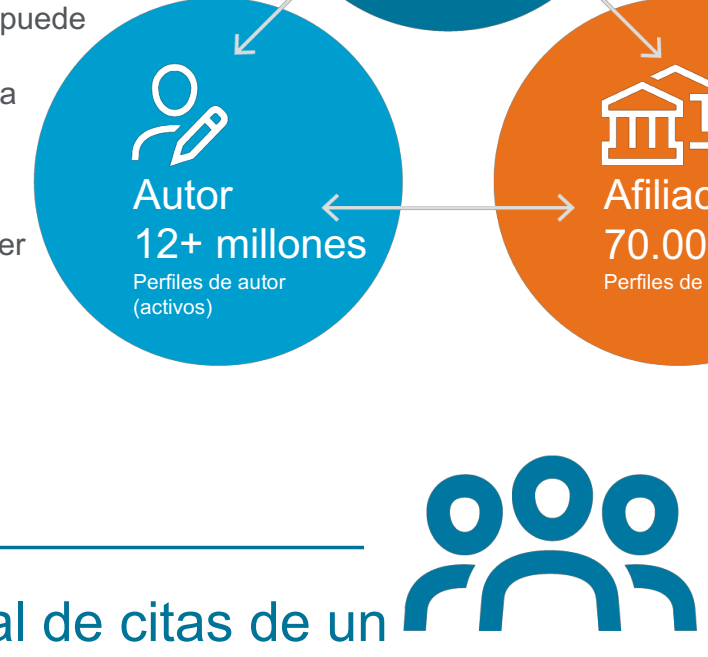

Los usuarios pueden analizar y rastrear el historial de citas de un individuo, ver su total de citas y documentos, h-index y más a través de páginas de perfil de autor.

Pueden acceder a las herramientas para obtener una visión general de la historia y la influencia de la publicación de un individuo.
Artículo $70+$ millones Registros de revistas, libros y series de libros, actas de congresos
publicaciones comerciales comerciales 


\section{Búsqueda de Autor}

\section{Author search}

To determine which author names should be grouped together under a single identifier number, the Scopus Author

Identifier uses an algorithm that matches author names based on their affliation, address, subject area, source title, dates

of publication, citations, and co-authors. Documents with insufficient data may not be matched, this can lead to more

than one entry in the results list for the same author. By default, only details pages matched to more than one document

in Scopus are shown in search results. About Scopus Author Identifier

Author last name

rodrigo

e.g. 5 muth

Affiliation

e.g. Unvarsity of Toronto

(i) ORCID

e.g. 1111-2222-3333-444x

Brought to you by

The Scopus Team
Author first name

$\mathrm{t}$

ag.h

$\square$ Show exact matches only

Search Q
Introduzca la afiliación para limitar el número de resultados 


\section{Búsqueda de Autor: resultados para unificar perfiles}

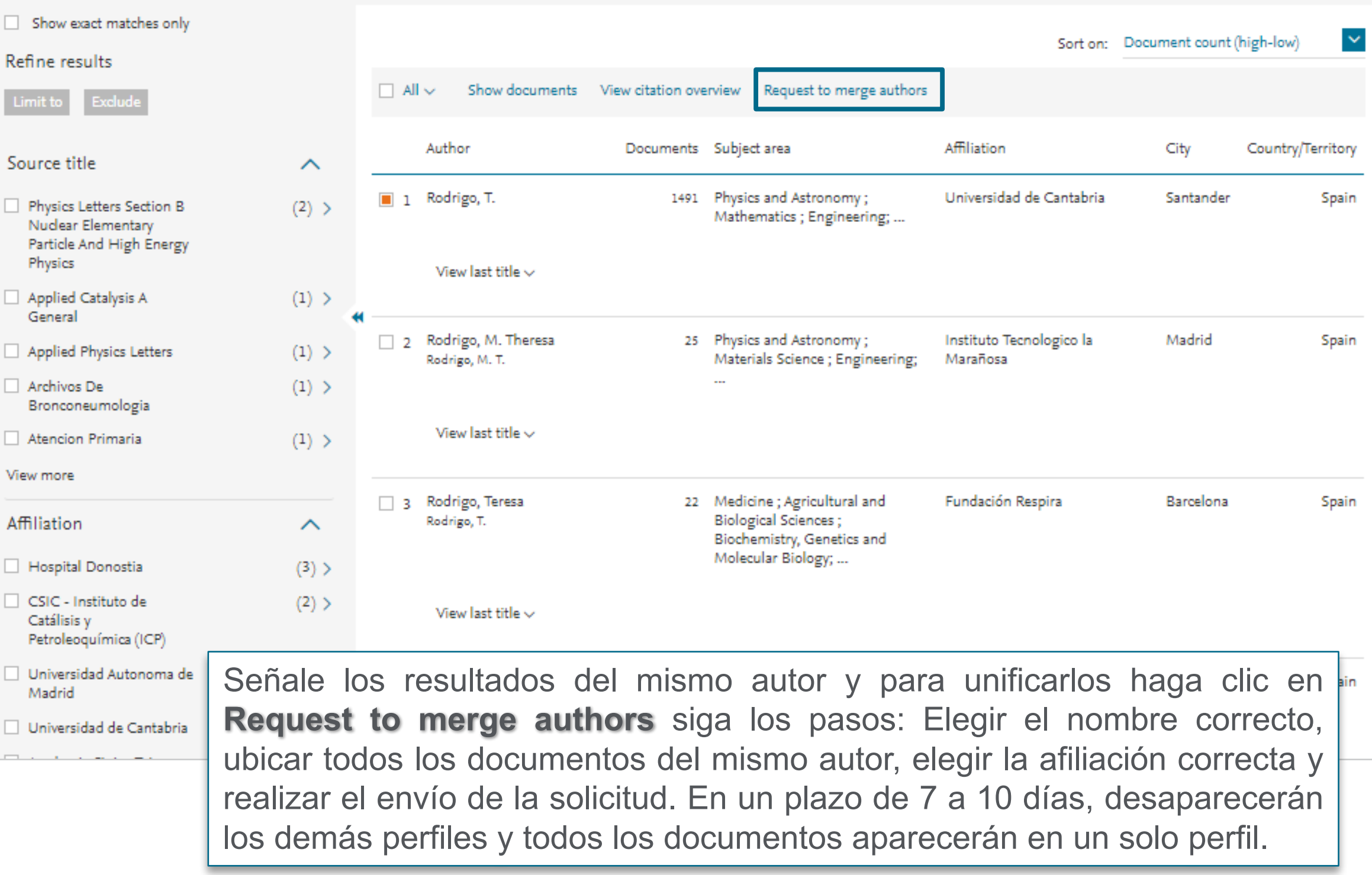




\section{Perfil de Autor}

\section{Author details}

About Scopus Author Identifier

〈Return to search results 〈Previous 2 of 1429 Next〉

吕Print 8 Email

Rodrigo, Manuel Andrés

Universidad de Castilla-La Mancha, Ciudad Real, Spain Author ID: 34868498800

(i) http://orcid_org/0000-0003-2518-8436

Other name formats: Rodrigo, Manual Rodrigo, Manual Andras Rodrigo-Rodrigo, Manual A. Rodrigo, Manual Andras Rodrigo, Manul A. Rodrigo, M. A.) Rodrigo, M.) Rodrigo, Manual A.R.) Rodrigo, Msnucl A.Rodrigo Rodrigo, Msnucl A.) Rodrigo Rodrigo, M. A.

Subject area: Environment:
Biochemistry,
View all $\checkmark$

Document and citation trends:

Haga clic aquí para solicitar correcciones en el perfil de autor

-

$\triangle$ Get citation alerts + Add to ORCID
Follow this Author

View potential author matches

$h$-index: (7)

56

Documents by author

383

Analyze author output

Total citations

11969 by 6033 documents

View citation overview

El Identificador de autor de Scopus asigna un número único a grupos de documentos escritos por el mismo autor a través de un algoritmo que coincide con la autoría en base a un criterio determinado. Si un documento no puede ser emparejado con seguridad con un identificador autor, que se agrupan por separado. En este caso, es posible que aparezca más de 1 entrada para el mismo autor. 


\section{Author Evaluator}

\section{Analyze author output}

About analyze author tool (2)

<Back to author details page

\section{Rodrigo, Manuel Andrés}

Universidad de Castilla-La Mancha, Ciudad Real, Spain Author ID:34868498800

Source $\downarrow$
Separation And Purification
Technology
Chemical Engineering Journal
Chemosphere
Electrochimica Acta
Industrial And Engineering
Chemistry Research
Journal Of Chemical Technology
And Biotechnology

Documents $\uparrow$

27

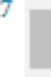

3

21

Biotechnolog

Journal Of Hazardous Mater

$$
h \text {-index }
$$

$56^{x^{2}}$

Journal Of Applied

Electrochemistry
23

23

23

23
Documents by source

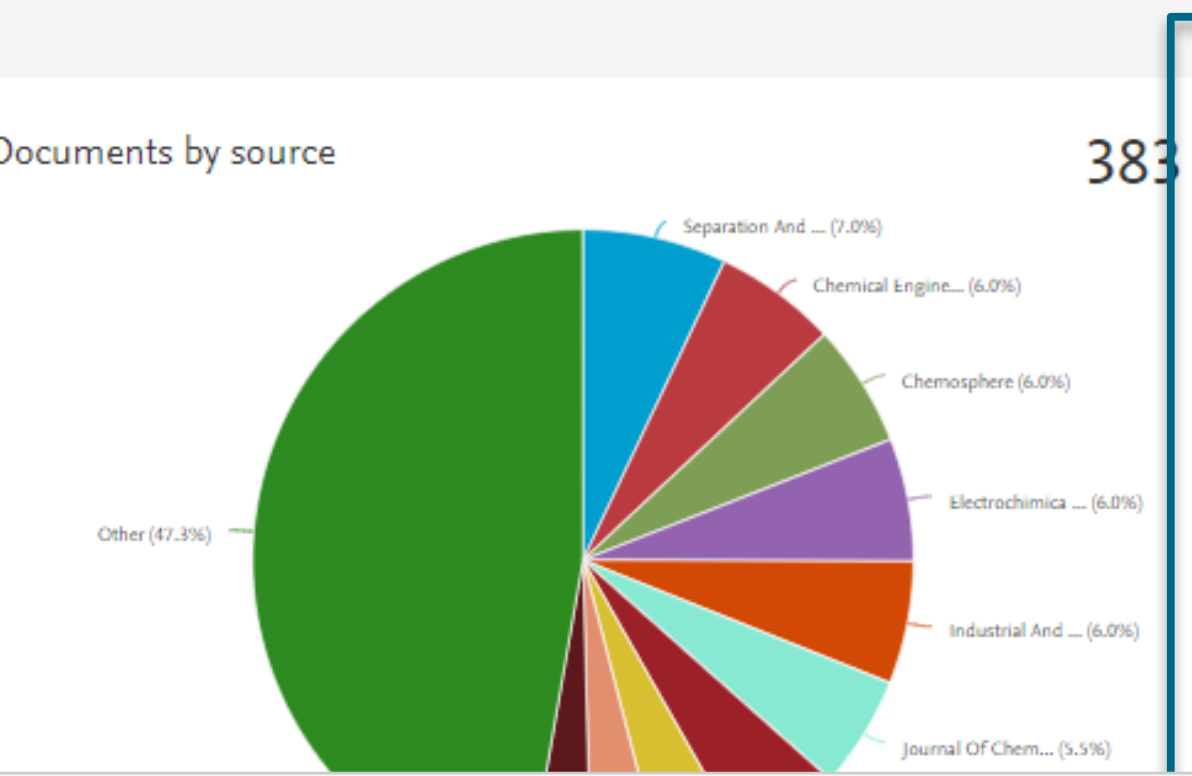

Citations $11.969^{k^{*}}$
By type

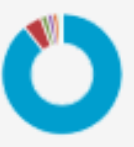

By year

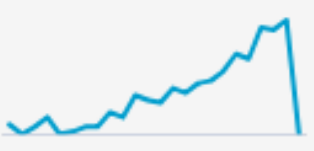

By subject

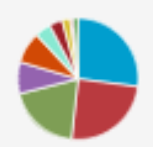

150 co-authors

$$
\text { Author Name }
$$$$
\text { Cañizares, Pablo Canizares }
$$

Co-3uthored Documents

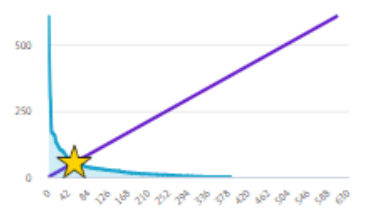

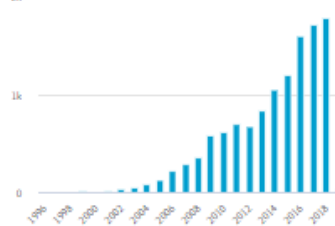

Sázz, Cristina

Lobato, Justo

Uanos, Javier

Fernandez-Morales, 


\section{El índice H - índice de Hirsch}

Publicado por Jorge E. Hirsch en Agosto de 2005. El índice H es una métrica que sirve para medir la productividad científica y el impacto del trabajo publicado por un investigador específico

En otras palabras:

Un autor con un índice $H$ de 13 tiene, al menos, 13 artículos publicados que recibieron, al menos, 13 citas.

\section{Analyze author output}

Back to author details page

Rodrigo, Manuel Andrés

Universidad de Castilla-La Mancha, Ciudad Real, Spain Author ID:34868498800

$\square$ Exclude self citations $\square$ Exclude citations from books

Update Graph

\begin{tabular}{lll} 
Documents $\downarrow$ & Citations $\downarrow$ Title $\downarrow$ \\
\hline 1 & 606 & Electrogeneration ... \\
\hline 2 & 455 & Electrochemical ad... \\
\hline 3 & 369 & Oxidation of 4-Chl... \\
\hline 4 & 300 & Electrochemical ox... \\
\hline 5 & 289 & Single and Couple... \\
\hline 6 & 203 & Costs of the electr... \\
\hline 7 & 170 & Coagulation and e... \\
\hline 8 & 166 & Removal of residu... \\
\hline 9 & 166 & Flectrochemiral Tr. \\
\hline
\end{tabular}

This author's $h$-index

The $h$-index is based upon the number of documents and number of citations.

800

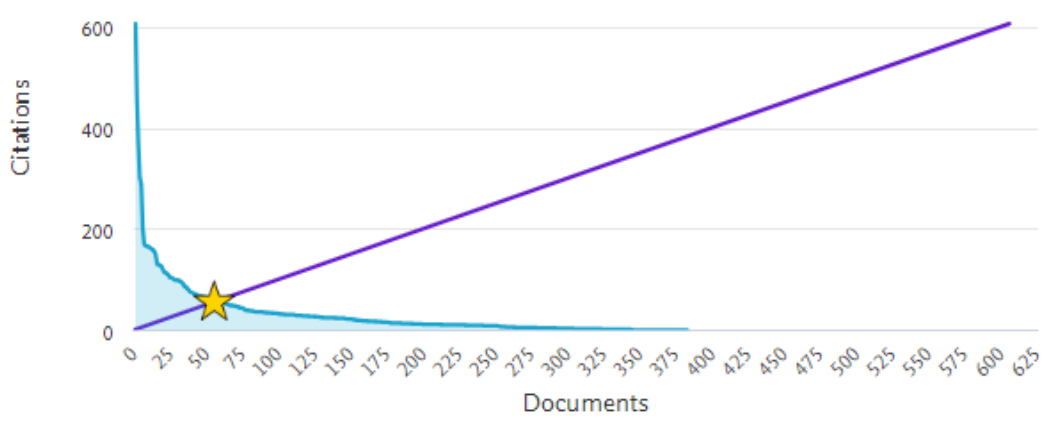




\section{Búsqueda de Afiliación}

\section{Affiliation search}

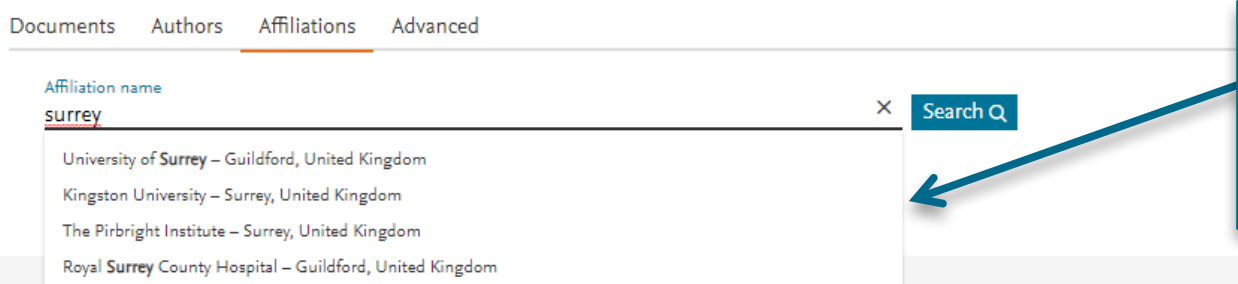

Introduzca el nombre de la afiliación y le saldrán diferentes opciones para elegir la correcta

Royal Surrey County Hospital - Guildford, United Kingdom

\section{Affiliation details - University of Surrey}

University of Surrey

Guildford

Surrey, United Kingdom

Affiliation ID: 60021097 University of Surrey Univ Of Surrey Univ. Surrey Univ. Of Surrey Surrey University University of Surrey Guildford
University of Surrey Roehampton

\section{$\rightarrow$ Export 合Print 8 Emai}

Documents, whole institution (i)

42,452

Documents, affiliation only

42,435

Authors

8,206
Documents by subject area Collaborating affiliations

Documents by source

\begin{tabular}{llll} 
& & & Sort by: \\
\hline Engineering & 9863 & Arts and Humanities \\
\hline Physics and Astronomy & 9299 & Agricultural and Biological Sciences \\
\hline Medicine & 6570 & Nursing \\
\hline Computer Science & 6008 & Earth and Planetary Sciences \\
\hline Materials Science & 4906 & Economics, Econometrics and Finance \\
\hline Social Sciences & 4519 & Energy \\
\hline Chemistry & 4429 & Immunology and Microbiology \\
\hline Biochemistry, Genetics and Molecular Bi... & 3928 & Neuroscience \\
\hline
\end{tabular}

Biochemistry, Genetics and Molecular Bi..
University of Surrey

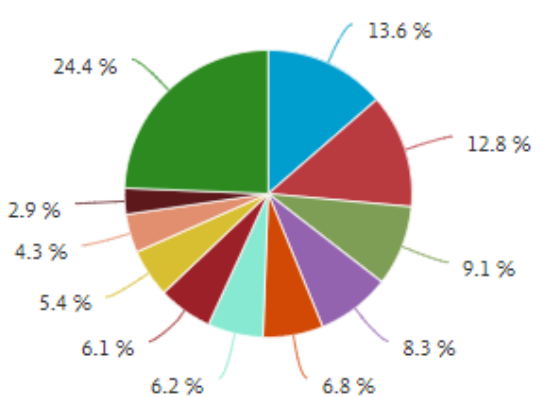




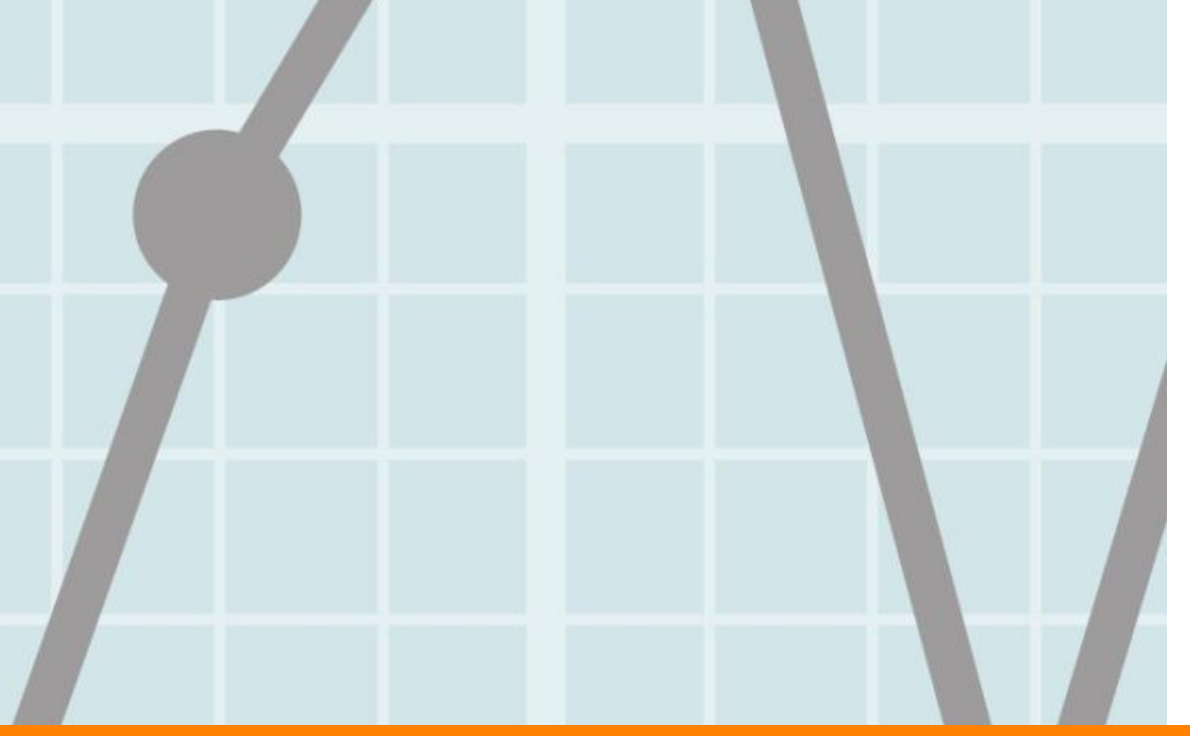

Métricas de investigación 


\section{Sources}

\section{Sources}

\begin{tabular}{l} 
Subject area \\
\hline Subject area \\
Title \\
Publisher \\
ISSN
\end{tabular}

\section{Display options \\ $\square$ Display only Open Access journals \\ $\square$ Display only souroe with \\ minimum 0 Documents \\ (previous 3 years) \\ Citescore highest quartile \\ $\square$ Show only titles in top 10 percent \\ $\square$ 1st quartile \\ $\square$ 2nd quartile \\ $\square$ 3rd quartile \\ $\square$ 4th quartile}

Source type

$\square$ Journals

$\square$ Book Series

$\square$ Conference Proceedings

$\square$ Trade Publications

25,469 results

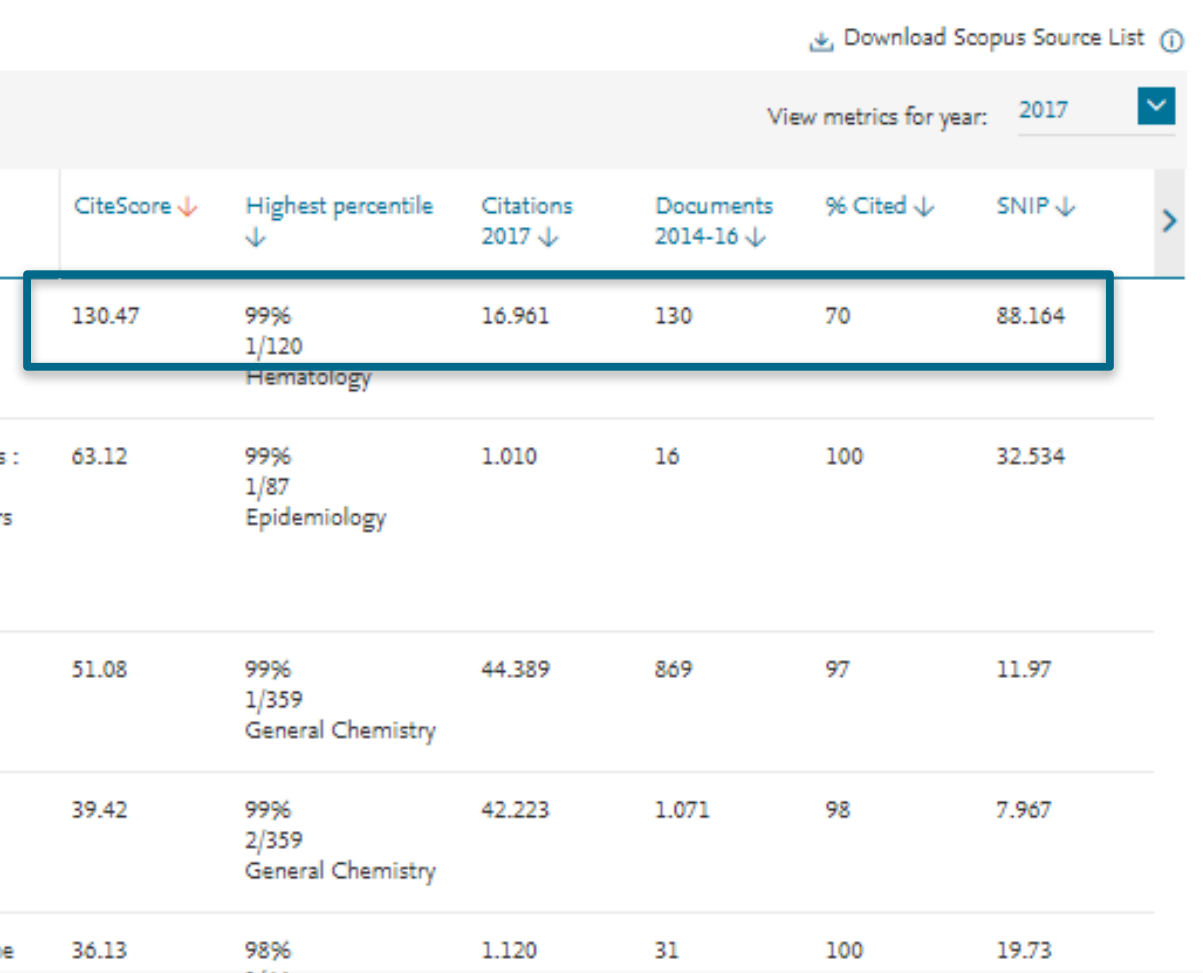

Source title $\downarrow$

Ca-A Cancer Journal for Clinicians

Copac F'B

$4 M$ MMWR. Recommendations and reports
Morbidity and mortality weekly report.
Recommendations and reports / Centers
for Disease Control Open Access

Copac $\square$ F'B
Chemical Reviews.

Chemical Society Reviews Copac FZB
- Copar

36.13 $98 \%$

National vital statistics reports : from the
Podemos buscar un título por área temática, título, editor o ISSN. Además filtrar dichos resultados por Acceso abierto (Open Access), cuartil al que pertenecen o por tipo de recurso 


\section{Compare Sources}

- Proporciona a los usuarios una visión comparativa entre diferentes fuentes de un mismo campo.

- Los datos objetivos se presentan de manera fácil, en forma de gráfico comparando las citas de hasta 10 publicaciones de revistas hasta la actualidad.

- Los datos se actualizan cada dos meses para asegurar su veracidad.

\section{Scopus}

Search

Sources

Alerts

Lists

Help $\checkmark$

Scival 7

Patricia Zevallos Tori $\vee$

\section{Document search}

Compare sources 


\section{CiteScore, SJR and SNIP: la cesta de métricas de Scopus}

\section{Compare sources}

Compare sources Search for and choose up to 10 sources to analyze and compare.

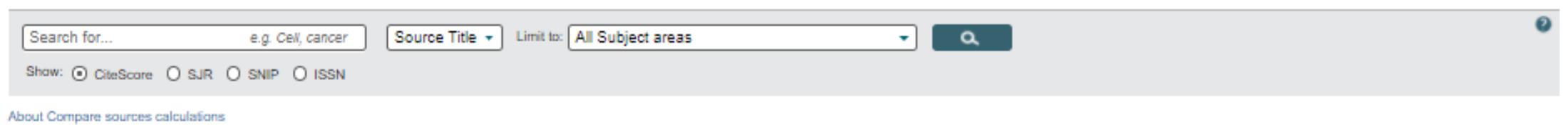

About Compare sources calculafons

\begin{tabular}{|l|l|}
\hline Source & Cite Score \\
\hline & $\begin{array}{c}\text { To add more data points to this graph, } \\
\text { please conduct a seach and select } \\
\text { items from the results list }\end{array}$ \\
\hline
\end{tabular}

\begin{tabular}{|c|c|c|c|c|c|c|}
\hline He chart & 皿 T. & & & & & \\
\hline CiteScore & SJR & SNIP & Citations & Documents & $\%$ Not cited & \% Reviews \\
\hline
\end{tabular}

Citescore Publication by year $\bullet$

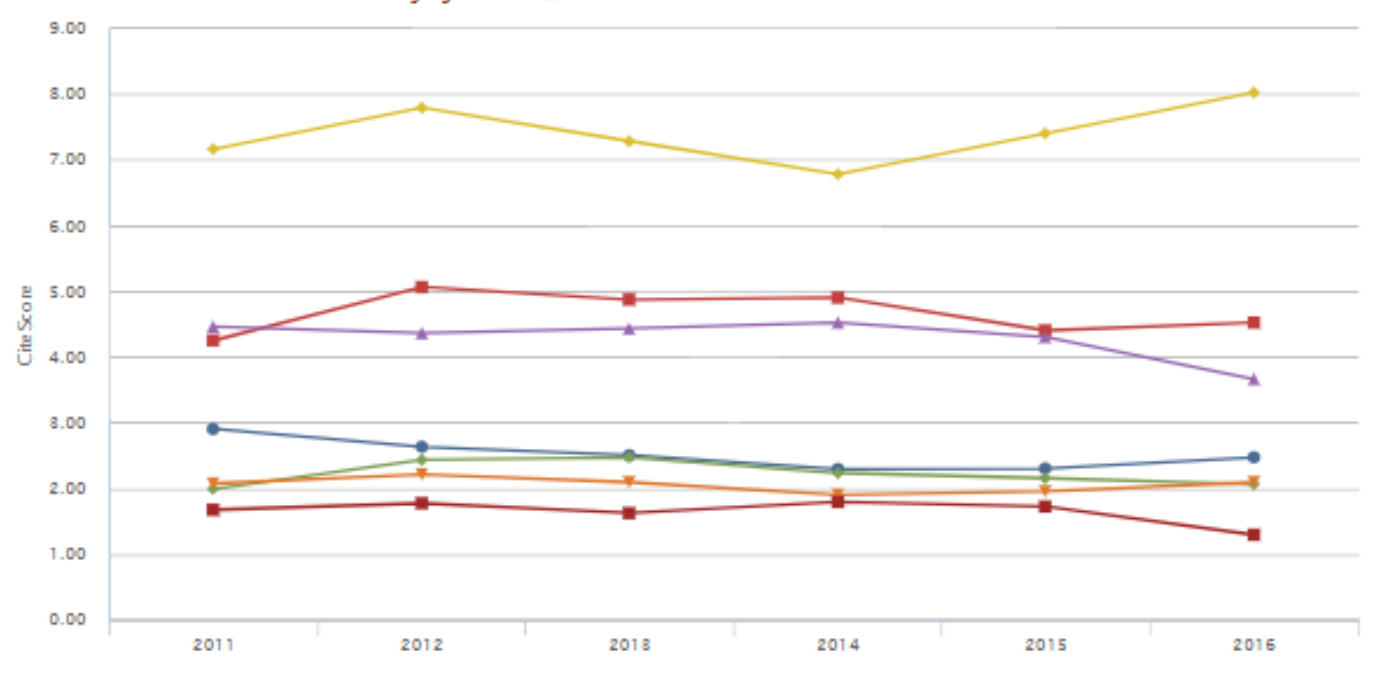

Q - Journal of Rhoumatology $\quad \square *$ Currant Opinion in Rhoumatology $\quad \square \rightarrow$ Clinical and Experimental Rhoumatology

Q - Arthritis Care and Research $\quad$ * Clinical Rheumatology $\quad \square$ - Podiatric Rheumatology

$\nabla+$ Annals of the Rheumatic Diseases 


\section{Las métricas de investigación de Elsevier en Scopus}

Un conjunto completo de métricas integradas en todo Scopus está diseñado para proporcionar una mejor visión de los intereses de investigación de los usuarios.

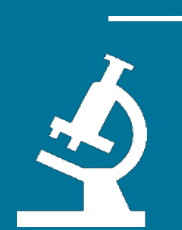

Dos reglas de oro para usar métricas de investigación Cuando se usan correctamente, las métricas de investigación junto con la información cualitativa brindan una visión equilibrada y multidimensional para la toma de decisiones

Utilice siempre tanto la información cualitativa como la cuantitativa en sus decisiones.
Utilice siempre más de una métrica de investigación como la entrada cuantitativa 


\section{Una cesta de métricas para la excelencia en la investigación}

\begin{tabular}{|c|c|c|}
\hline \multirow{10}{*}{ 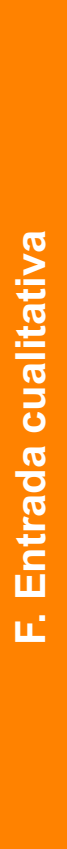 } & Tema & Sub-tema \\
\hline & A. Financiación & Premios \\
\hline & B. Producción & Productividad de los resultados de la investigación \\
\hline & & Visibilidad de los canales de comunicación \\
\hline & C. Impacto de la Investigación & Influencia de la investigación \\
\hline & & Transferencia de conocimiento \\
\hline & D. Compromiso & Red académica \\
\hline & & Red no académica \\
\hline & & Transferencia de experiencia \\
\hline & E. Impacto Social & Impacto social \\
\hline
\end{tabular}

Disponible para artículos, investigadores, revistas, instituciones, áreas temáticas... 


\section{Journal metrics (Métrica de revistas) en Scopus}

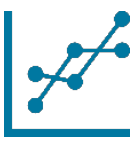

\section{Powered by Scopus ${ }^{\circ}$}

Las métricas CiteScore ${ }^{\mathrm{TM}}$ son el nuevo estándar que ayuda a medir el impacto de las citas de revistas.

- Métricas completas, transparentes, actuales y gratuitas para ayudar a analizar dónde se publican los resultados de la investigación.

- Utilizando los datos de Scopus, las métricas CiteScore ayudan a validar citas recibidas por revistas y actas, y facilitan a los usuarios con información para tomar decisiones bien informadas sobre dónde publicar.
Source-Normalized Impact per Paper (SNIP)

- Desarrollado por CWTS, Universidad de Leiden, Países Bajos.

- Mide el impacto de citas contextuales al ponderar las citas en función del número total de citas en un campo temático.

- El impacto de una sola cita tiene mayor valor en las áreas temáticas donde las citas son menos probables, y viceversa.

SCImago Journal Rank (SJR)

- Desarrollado por SCImago, España.

- Una métrica de prestigio que se puede aplicar a revistas, series de libros y actas de congresos.

- Con SJR, el campo temático, la calidad y la reputación de la revista tienen un efecto directo sobre el valor de una cita. 


\section{CiteScore proporciona una mayor transparencia, modernidad y exhaustividad}

\section{2,618}

active titles and growing

$11,698_{\text {titles }}$ CiteScore increased or staye
the same from 2015- 2016

\section{$1,059_{\text {titles }}$} CiteScore more than doubled
between $2015-2016$

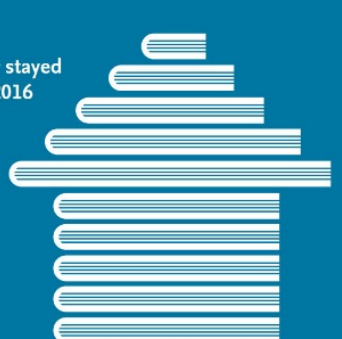

330

disciplines

Analytical Chemistry

Microbiology
Medicien Physical Sciences

Decision Sciences Embryology General Medicine Histology Health Sciences Conservation Automotive Engineering Immunology Geology Social Sciences Bioengineering Endocrinology Plant Science

2,091
2,855

top $10 \%$ titles

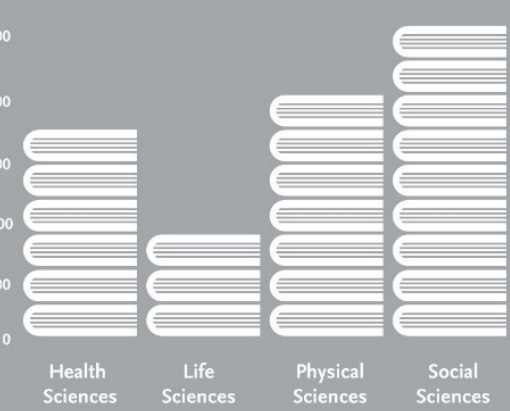

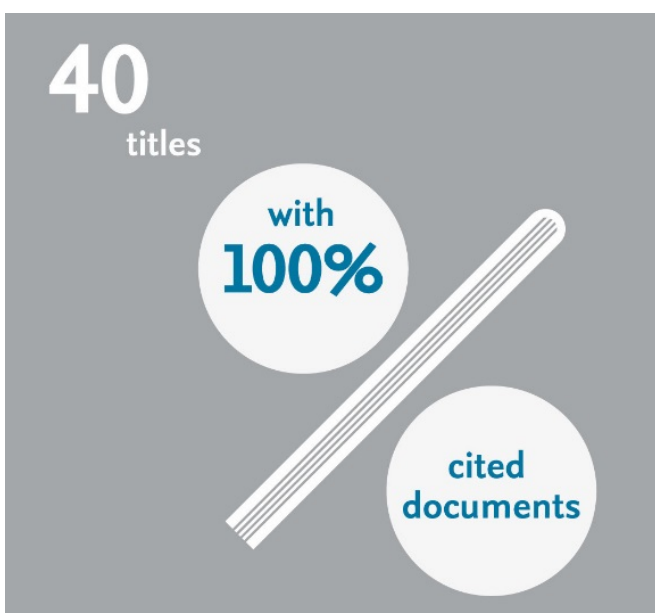

\section{Highest metric scores}

Highest citation and document counts

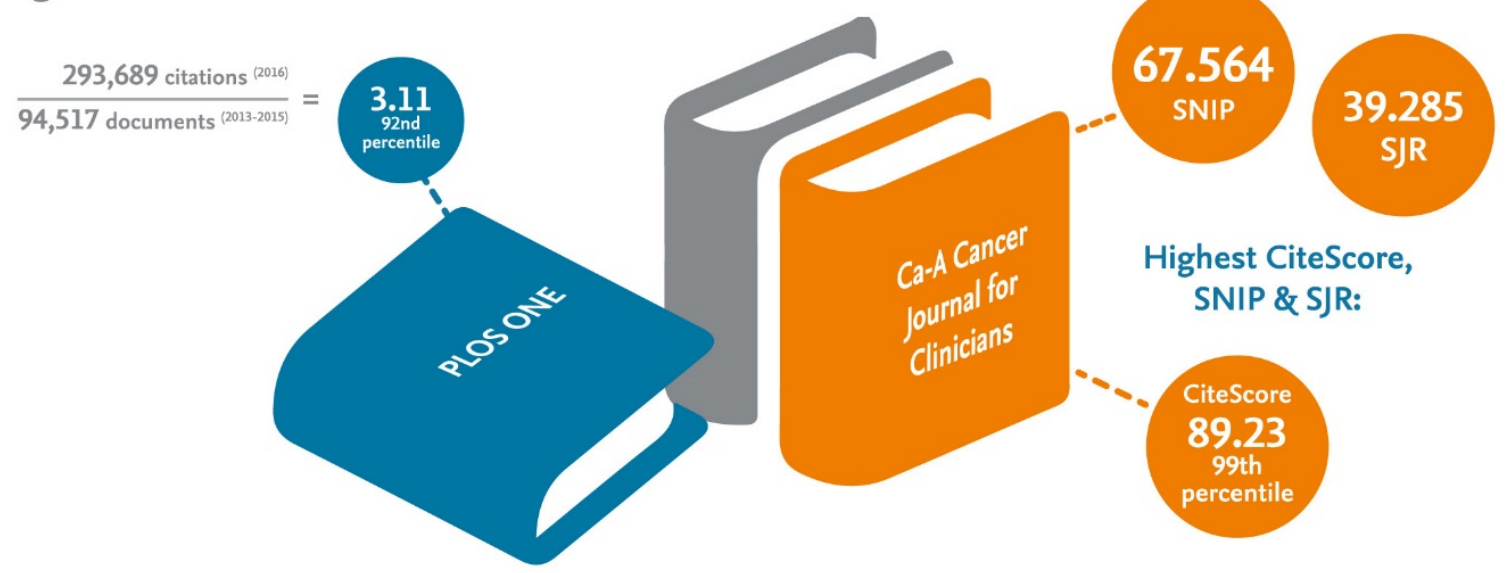




\section{CiteScore es una métrica simple para todas las revistas en Scopus}

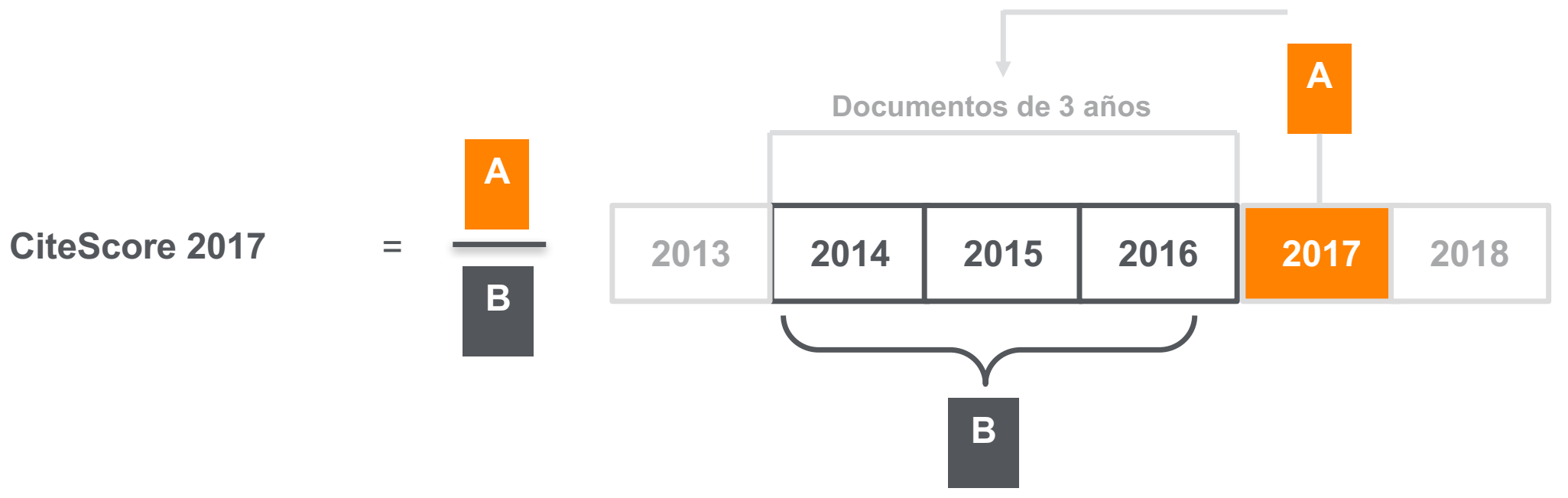

\begin{tabular}{l|l}
\hline CiteScore & Impact Factor \\
\hline$A=$ citas a 3 años de documentos & $A=$ citas a 2 o 5 años de documentos \\
$\begin{array}{ll}B=\text { todos los documentos indexados en Scopus, } \\
\text { lo mismo que } A\end{array}$ & $\begin{array}{l}B=\text { solo artículos citables (artículos y reseñas), } \\
\text { diferentes de } A\end{array}$
\end{tabular}




\section{Cada métrica proporciona una medida complementaria de rendimiento}

\begin{tabular}{|c|c|c|c|c|c|c|}
\hline & Medidas & $\begin{array}{l}\text { Validation in } \\
\text { Scopus? }\end{array}$ & $\begin{array}{l}\text { Size- } \\
\text { normalized? }\end{array}$ & $\begin{array}{l}\text { Subject field- } \\
\text { normalized? }\end{array}$ & $\begin{array}{l}\text { Communicate } \\
\text { s magnitude? }\end{array}$ & $\begin{array}{l}\text { Update } \\
\text { frequency }\end{array}$ \\
\hline CiteScore & Citas por documento & $\mathrm{Si}$ & $\mathrm{Si}$ & No & $\mathrm{Si}$ & \multirow{5}{*}{$\begin{array}{l}\text { Anualmente y } \\
\text { mensualmente } \\
\text { para las } \\
\text { métricas de } \\
\text { CiteScore } \\
\text { Tracker }\end{array}$} \\
\hline $\begin{array}{l}\text { CiteScore } \\
\text { Percentile }\end{array}$ & $\begin{array}{l}\text { Posición relativa dentro } \\
\text { del campo temático según } \\
\text { CiteScore }\end{array}$ & $\mathrm{Si}$ & $\mathrm{Si}$ & $\mathrm{Si}$ & No & \\
\hline $\begin{array}{l}\text { Citation } \\
\text { Count }\end{array}$ & $\begin{array}{l}\text { Impacto bruto de una } \\
\text { revista en la comunidad } \\
\text { de investigación }\end{array}$ & $\mathrm{Si}$ & No & No & $\mathrm{Si}$ & \\
\hline $\begin{array}{l}\text { Document } \\
\text { Count }\end{array}$ & $\begin{array}{l}\text { Escala bruta de un título } \\
\text { dentro de la comunidad } \\
\text { de investigación }\end{array}$ & $\mathrm{Si}$ & No & No & $\mathrm{Si}$ & \\
\hline$\%$ cited & $\begin{array}{l}\text { Consistencia con la que } \\
\text { los contenidos de un título } \\
\text { se citan de manera } \\
\text { confiable }\end{array}$ & Si & Si & No & No & \\
\hline SNIP & $\begin{array}{l}\text { Citas relativas por } \\
\text { documento }\end{array}$ & No & Si & Si & No & \multirow{2}{*}{ Anualmente } \\
\hline SJR & Prestigio de citar fuentes & No & $\mathrm{Si}$ & $\mathrm{Si}$ & No & \\
\hline
\end{tabular}




\section{Métricas a nivel de artículo en Scopus: PlumX Comparar Me gusta con Me gusta}

PlumX Metrics son medidas integrales, a nivel de ítem que proporcionan información sobre las formas en que las personas interactúan con los resultados individuales de la investigación:

- Visualiza el compromiso académico

- Incluye 5 categorías de métricas

- Diseñado para comunicar el compromiso sin puntaje

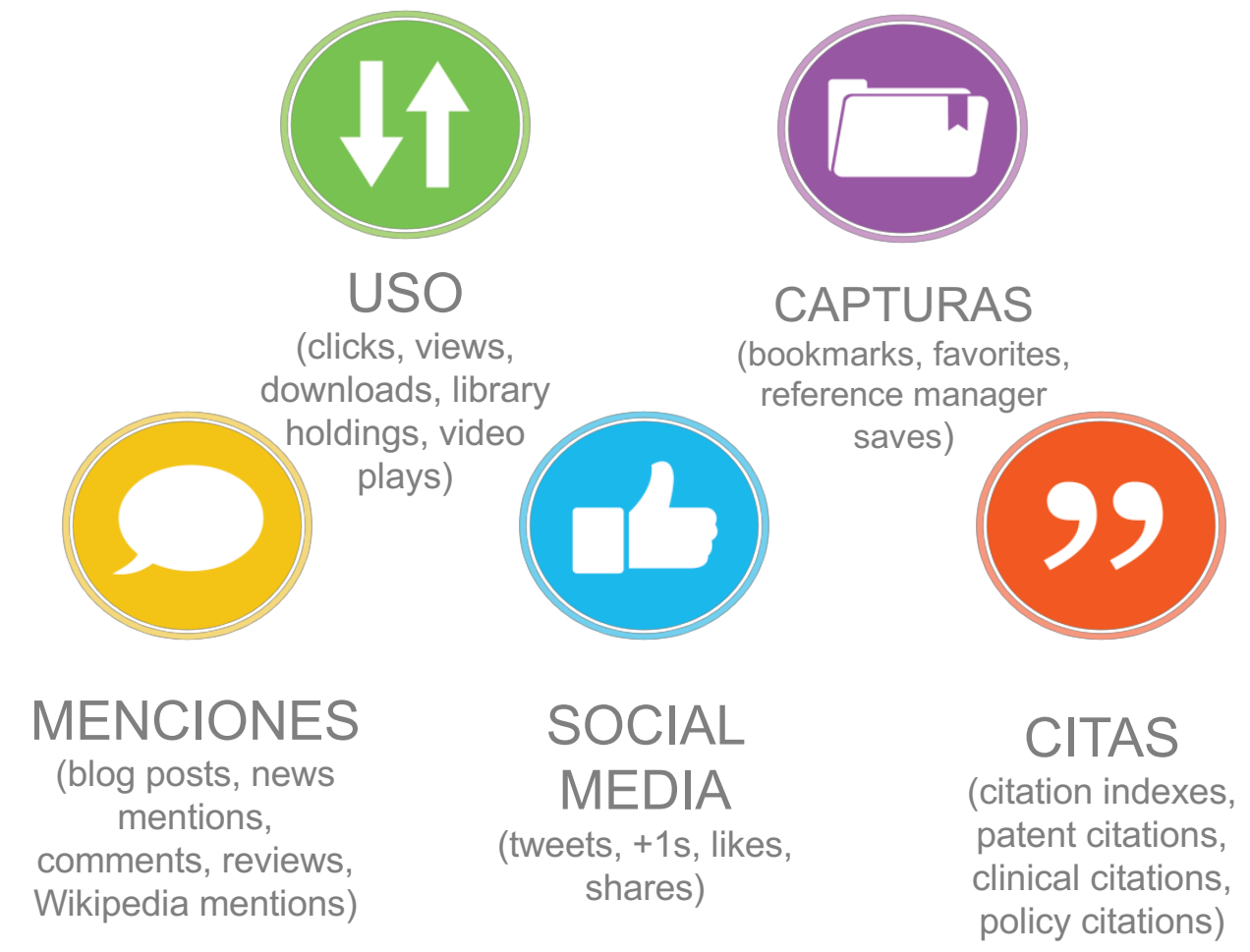

PlumX en Scopus:

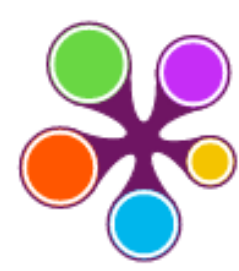

épLUmX

Usage

Clicks: 814

Abstract Views: 960

HTML Views: 192

Link-outs: 131

Captures

Exports-Saves: 72

Readers: $\mathbf{8 6}$

Mentions

Blog Mentions: 3

Comments: 8

Links: 1

Social Media

Shares: 23

Likes: 12

+1s: 9

Score: 4

Tweets: 114

Citations

Clinical Citations: $\mathbf{4}$

Citations: 298

see details 
Novedades

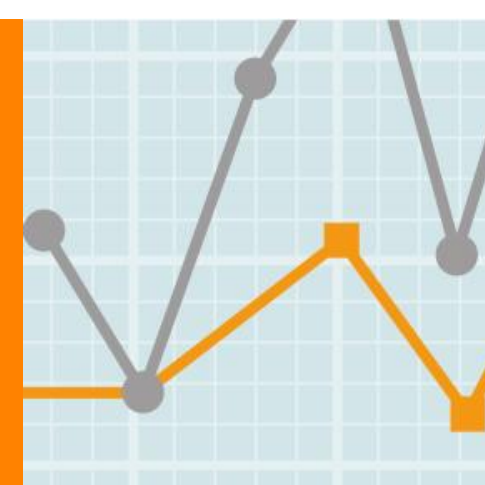




\section{Temas relevantes (topics prominence)}

- ¿Qué son?

- 100k Temas computados en SciVal basados en el análisis de red de citas

- Cada tema está asociado con una puntuación según la prominencia (basada en los recuentos de citas, visitas en Scopus y el promedio de CiteScore) que representa su estado de relevancia

- En las páginas de registro: cada artículo incluido en SciVal está asociado a un tema

- ¿Para qué sirven?

- Mejorar el periplo para la búsqueda y localización de literatura científica (a través de la ventana del Tema)

- Ayudar a los autores a mostrar su contribución a un tema de investigación específico

- En definitiva: proporcionar una clasificación más granular que la de ASJC centrada en el documento, para el análisis bibliométrico. 


\section{Temas prominentes}

\section{the limit of zero disorder (Article)}

Richter, C. ${ }^{a}, \quad$ Schmiedeberg, M. ${ }^{b}$ 芉, Stark, H. ${ }^{a} \curvearrowleft$

aInstitut für Theoretische Physik, Technische Universität Berlin, Hardenbergstr. 36, Berlin D-10623, Germany

bInstitut für Theoretische Physik 2: Weiche Materie, Heinrich-Heine-Universität Düsseldorf, Düsseldorf D-40204, Germany

\section{Abstract}

We study a colloidal model syste large disorder where geometrica only move on single lines which exhibits a solid-to-fluid transitio neighbors on neighboring lines. height of the pair correlation fun and the screening length at whic EDP Sciences, SIF, Springer-Verl

\section{New: Scival Topic Prominence}

Topics are unique areas of research, created using all Scopus documents from 1996 onwards.

Use these Topics to discover related documents, high momentum and most likely high funding success rates.

Learn more in the Support Center find potential collaborators and explore Topics with

\section{SciVal Topic Prominence (i)}

Topic: Colloids glass colloidal gels

Prominence percentile: 63.2

3.2 $\times$ corresponding to a system that can crystallize - to les with screened electrostatic repulsion. They can by modulating the particle line density. The system on of the mean-square distance of nearest disorder is tuned to zero. We observe that the peak verfect crystal. Similarly, the mean interaction energy $n$ the limit of zero disorder is approached. (c) 2011

\section{क}

\section{PlumX Metrics}

Usage, Captures, Mentions, Social Media and Citations

\section{Cited by 1 document}

beyond Scopus.

Orientational ordering, buckling, and dynamic transitions for vortices interactin with a periodic quasi-one-dimensional substrate

Le Thien, Q. , McDermott, D. , Olson Reichhardt, C.J.

(2016) Physical Review B

View details of this citation

Inform me when this document is cited in Scopus:

\begin{tabular}{|l|l|}
\hline Set citation alert $>$ Set citation feed $>$ \\
\hline
\end{tabular}

\section{Indexed keywords}

Compendex keywords

$$
\begin{aligned}
& \text { Colloidal particle Geometrical frustrations Interaction energies Line density Mean-square Model system } \\
& \text { Nearest neighbors) (Pair correlation functions) Peak height) (Perfect crystals) Screened electrostatic repulsion ) }
\end{aligned}
$$

\section{Related documents}

Freezing and melting of a colloidal 


\section{Temas prominentes}

Topic: Colloids | glass | colloidal gels (T.6129)

Year range: $2012-2017$

\section{Representative documents}

Liquids, freezing, and the glass transition

Smith, J., L, R. Do., King J. L...

(2016) Physical Review

Cited 888 times

Lorem ipsum dolor sit amet, consectetur adipiscing elit, sed do eiusmod tempor incididunt ut labore et dolore magna aliqua. Ut enim ad minim veniam

Smith, J., L, R. Do., King J. L...

(2016) Physical Review

Cited 312 times

Lorem ipsum dolor sit amet, consectetur adipiscing elit, sed do eiusmod tempor

Smith, J., L, R. Do., King J. L...

(2016) Physical Review

Cited 302 times

Lorem ipsum dolor sit amet, consectetur adipiscing elit, sed do eiusmod tempor incididunt ut labore et dolore magna aliqua. Ut enim ad minim veniam

Smith, J., L, R. Do., King J. L...

(2016) Physical Review

Cited 120 times

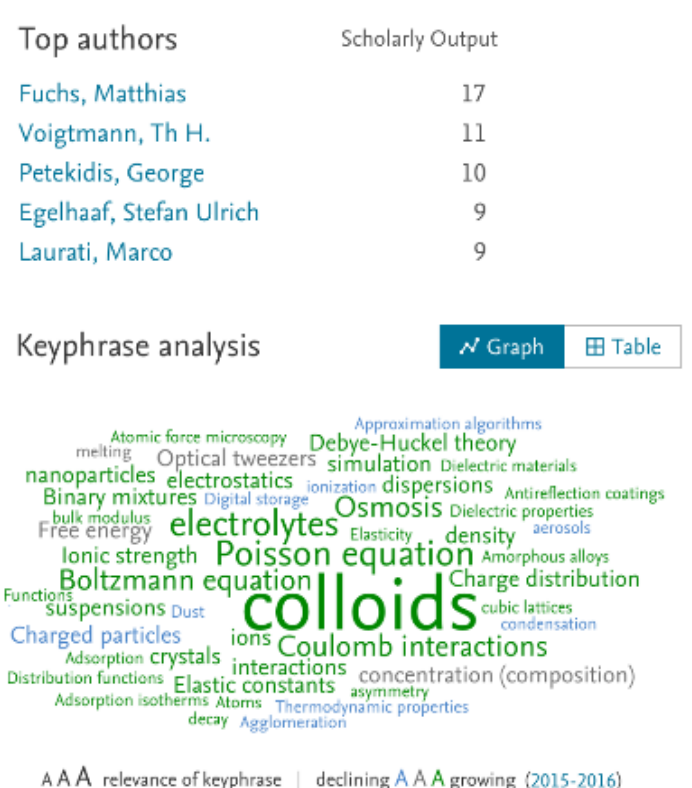

Analyze in Scival $>$ 


\section{Temas prominentes}

\begin{tabular}{|l|l|}
\hline Un tema es una colección de documentos con un interés intelectual \\
común, un "problema de investigación"
\end{tabular}

Los temas son dinámicos y pueden evolucionar.

Nuevos temas pueden nacer.

\begin{tabular}{|c|c|}
\hline$\hat{k y}$ & Muchos temas son inherentemente multidisciplinares. \\
\hline 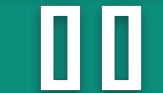 & Los viejos temas pueden estar inactivos, pero todavía existentes \\
\hline ogo & $\begin{array}{l}\text { Los investigadores tienen movilidad y pueden contribuir a múltiples } \\
\text { temas. }\end{array}$ \\
\hline
\end{tabular}




\section{Nuevas opciones de búsqueda: Agencias de financiación}

Search within results...

Refine results

\section{Limit to Exclude}

Funding sponsor

$\square$ National Natural Science Foundation of China (NSFC)

$\square$ National Institutes of Health $(\mathrm{NIH})$

$\square$ National Science Foundation (NSF)

$\square$ Deutsche

Forschungsgemeinschaft (DFG)

$(175,662)>$

Japan Society for the Promotion of Science (JSPS)

$(598,989)>$

$(538,554)>$

$(209,474)>$
吅 Analyze search results

Show all abstracts Sort on: Date (newest)

... 吕四 즘

Document title

Authors

Year Source

Cited by

2020 Artificial Intelligence and Big Data: The Birth of a

New Intelligence

8, pp. 1-117

Artificial Intelligence
Intelligence ( 0 ] Book)

lafrate, F.

View abstract $\vee \quad$ Related documents Doc-XML SOLR-JSON

$\square 2$ Physical model test and evaluation for the tunnel

Hao, X.-J., Yuan, L., Xue,

stability influenced by magnitude and path of loading

, (...), Zhang, X.-Y.,

Li, Y.-L.

2020 Journal of Testing and

Evaluation

$48(2)$

View abstract $\vee$ Related documents Doc-XML SOLR-JSON

$\square 3$ Common fixed point theorems in Gb-metric space

Shen, Y., Zhu, C., Wu, Z.
2019 Journal of Computational Analysis and Applications 27(7), pp. 1083-1090




\section{Agencias de financiación: nueva estructura de datos}

\begin{tabular}{|c|c|c|}
\hline \multicolumn{3}{|c|}{ Previous } \\
\hline \multicolumn{3}{|l|}{ Funding details } \\
\hline Funding sponsor & Funding number & Acronym \\
\hline $\begin{array}{l}\mathrm{NIH} \text { Office of the Director } \\
\text { See opportunities by OD }\end{array}$ & & OD \\
\hline Pioneer Hi-Bred & DP1-MH100706 & \\
\hline Pioneer Hi-Bred & Previously, funding & \\
\hline $\begin{array}{l}\text { Howard Hughes Medical Institute } \\
\text { See opportunities by HHMIJ }\end{array}$ & $\begin{array}{l}\text { information displayed } \\
\text { each funding arant and }\end{array}$ & нНмі \\
\hline Life Sciences Research Foundatio, & sponsor separately. & LSRF \\
\hline $\begin{array}{l}\text { National Institutes of Health } \\
\text { See opportunities by } \mathrm{NIH} \lambda\end{array}$ & & $\mathrm{NIH}$ \\
\hline $\begin{array}{l}\text { National Institutes of Health } \\
\text { See opportunities by } \mathrm{NIH} \lambda\end{array}$ & R01-GM34277 & $\mathrm{NIH}$ \\
\hline \multirow[t]{2}{*}{$\begin{array}{l}\text { National Institutes of Health } \\
\text { See opportunities by NIH }\end{array}$} & R01-CA133404 & $\mathrm{NIH}$ \\
\hline & PN2EY018244 & \\
\hline \multicolumn{3}{|c|}{$\begin{array}{l}\text { Daman Runyon Cancer Research Foundation } \\
\text { See opportunities } \lambda\end{array}$} \\
\hline Massachusetts Institute of Technol & & MIT \\
\hline
\end{tabular}

\begin{tabular}{|c|c|c|}
\hline \multicolumn{3}{|c|}{ New } \\
\hline Funding details & & \\
\hline Funding sponsor & Funding number & Acronym \\
\hline $\begin{array}{l}\mathrm{NIH} \text { Office of the Director } \\
\text { See opportunitites by } \mathrm{OD} \lambda\end{array}$ & \multirow{4}{*}{$\begin{array}{l}\text { Now, all funding grants } \\
\text { belonging to the same } \\
\text { sponsor have been } \\
\text { consolidated into a single } \\
\text { line. }\end{array}$} & OD \\
\hline Pioneer Hi-Bred & & \\
\hline $\begin{array}{l}\text { Howard Hughes Medical Institute } \\
\text { See opportunities by HHMI/ }\end{array}$ & & ннмІ \\
\hline Life Sciences Research Foundation & & LSRF \\
\hline $\begin{array}{l}\text { National Institutes of Health } \\
\text { See opportunities by NitH }\end{array}$ & & $\mathrm{NIH}$ \\
\hline \multirow[t]{2}{*}{$\begin{array}{l}\text { National Institutes of Health } \\
\text { See opportunities by } \mathrm{NIH} T\end{array}$} & R01-GM34277,R01-CA133404 & $\mathrm{NIH}$ \\
\hline & PN2EY018244 & \\
\hline \multicolumn{3}{|c|}{$\begin{array}{l}\text { Damon Runyon Cancer Research Foundation } \\
\text { See opportunities } 7\end{array}$} \\
\hline Massachusetts Institute of Technology & & MIT \\
\hline
\end{tabular}




\section{Opción de refinar los resultados en la búsqueda de patentes}

Scopus $\quad \underline{\text { Search }}$ Sources Alerts Lists Help $\vee$ SciVal $\pi \quad$ Register $>$ Login $\vee \equiv$

\section{8,926 document results}

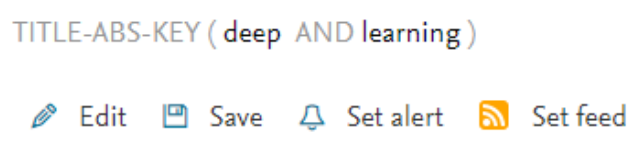

Search within results...

Refine results

\section{Limit to Exclude}

Access type (i)

$\square$ Open Access

$\square$ Other

$(1,556)>$

$(37,370)>$
매을 Analyze search results

Show all abstracts

Sort on:

Date (newest)

$\checkmark$

$\square$ All $\vee$ Export Download View citation overview View cited by Add to List $\cdots$ 合西 므
Document title

Authors

ao, Y., Guan, D., Huang, W.

(...), Cao, Y., Qiao, Y.

trian detection with unsupervised multispectral
Year Source

Cited by

2019 Information

Fusion

46, pp. 206-217

4 View abstract $\vee$ View at Publisher Related documents 


\title{
Opción de refinar los resultados en la búsqueda de patentes
}

\author{
Scopus \\ Search Sources \\ Alerts Lists Help $\vee \quad$ SciVal $\pi$ \\ Register $>$ \\ Login $\vee \equiv$
}

\section{4,436 patent search results}

TITLE-ABS-KEY (deep AND learning)

Search within results.

Q

Refine results

Limit to Exclude

Year

$\square 2018$

$\square 2017$

$\square 2016$

$\square 2015$

$\square 2014$

View more

\begin{tabular}{lc} 
Patent Office & \multicolumn{1}{c}{$\wedge$} \\
$\square$ United States Patent \& & $(37,153)>$ \\
$\quad$ Trademark Office & \\
$\square$ Japan Patent Office & $(9,681)>$ \\
$\square$ World Intellectual \\
$\quad$ Property Organization \\
$\square$ European Patent Office & $(4,593)>$ \\
$\square$ United Kingdom & $(2,582)>$ \\
& $\begin{array}{l}\text { Intellectual Property } \\
\text { Office }\end{array}$ \\
\end{tabular}

Limit to Exclude
$(6,332)>$

$(8,021)>$

$(5,432)>$

$(4,106)>$

$(3,613)>$

$\wedge$

(8) >

427) $>$
<Back to document results

Sort on: Date (newest)

$\checkmark$

Show all information

\begin{tabular}{|c|c|c|c|c|c|}
\hline & Patent name & Inventor(s)/applicant(s) & Year & Patent office & Patent number \\
\hline \multirow[t]{2}{*}{1} & $\begin{array}{l}\text { DISTRIBUTED DEEP LEARNING DEVICE AND } \\
\text { DISTRIBUTED DEEP LEARNING SYSTEM }\end{array}$ & $\begin{array}{l}\text { Akiba, Takuya (Preferred Networks, } \\
\text { Inc.) }\end{array}$ & 2018 & $\begin{array}{l}\text { United States } \\
\text { Patent and } \\
\text { Trademark Office } \\
\text { Pre-Granted } \\
\text { Publication }\end{array}$ & US20180211166 \\
\hline & Show more information $\vee$ 'LexisNexis' & & & & \\
\hline \multirow[t]{2}{*}{2} & $\begin{array}{l}\text { INFORMATION PROCESSING APPARATUS, } \\
\text { INFORMATION PROCESSING METHOD AND } \\
\text { RECORDING MEDIUM }\end{array}$ & $\begin{array}{l}\text { TANAKA, Takuya; KASAHARA, } \\
\text { Ryosuke (Ricoh Company, Ltd.) }\end{array}$ & 2018 & $\begin{array}{l}\text { United States } \\
\text { Patent and } \\
\text { Trademark Office } \\
\text { Pre-Granted } \\
\text { Publication }\end{array}$ & US20180211374 \\
\hline & Show more information $\vee$ 'LexisNexis' & & & & \\
\hline \multirow[t]{2}{*}{3} & $\begin{array}{l}\text { CLASSIFYING BIOLOGICAL SAMPLES USING } \\
\text { AUTOMATED IMAGE ANALYSIS }\end{array}$ & $\begin{array}{l}\text { Tandon, Tanay; Bodapati, Deepika; } \\
\text { Tandon, Utkarsh (WYATT,) }\end{array}$ & 2018 & $\begin{array}{l}\text { United States } \\
\text { Patent and } \\
\text { Trademark Office } \\
\text { Pre-Granted } \\
\text { Publication }\end{array}$ & US20180211380 \\
\hline & Show more information $\vee{ }^{\prime}$ LexisNexis' & & & & \\
\hline 4 & $\begin{array}{l}\text { Automated Evidence Based Identification of } \\
\text { Medical Conditions and Evaluation of Health } \\
\text { and Financial Benefits Of Health Management } \\
\text { Intervention Programs }\end{array}$ & $\begin{array}{l}\text { Zarkoob, Hadi; Kapashi, Harshna; } \\
\text { Menon, Prakash(...) (BaseHealth, Inc.) }\end{array}$ & 2018 & $\begin{array}{l}\text { United States } \\
\text { Patent and } \\
\text { Trademark Office } \\
\text { Pre-Granted }\end{array}$ & US20180211727 \\
\hline
\end{tabular}




\section{El acceso abierto a nivel de artículo 8,5 millones de artículos (iy sumando!)}

- Los datos de OA a nivel de documento de la base de datos Unpaywall de Impactstory ahora se integran con el contenido de Scopus, lo que aumenta la cantidad de contenido etiquetado como OA en Scopus a más de 8,5 millones de registros y sumando.
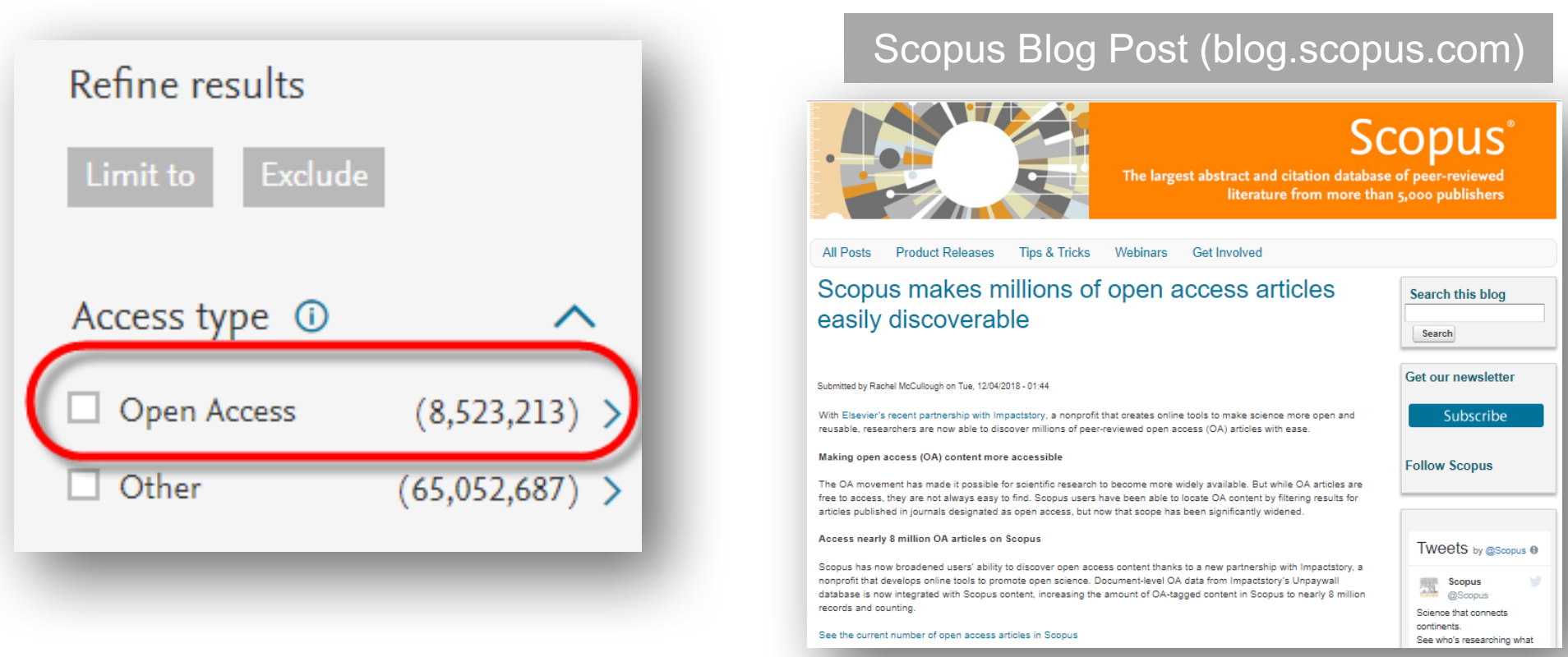


\section{Los primeros artículos en prensa con referencias han comenzado a aparecer en Scopus. Ejemplo}

\section{Document details}

$<$ Back to results | 1 of 1

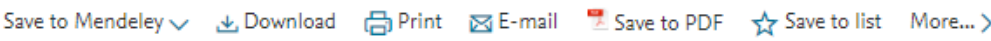

Full Text $\square$ Copac Dissys $x$

Youth and Society

2018

Pathways to Armenian Youth Empowerment in Low Socioeconomic Communities: Indiroct Effoctc of Parenting and Moderating Effects of Gender

(谓 Article in press ? )

Devenish, B. 8, Hooley, M., Stokes, M., Mellor, D. ㅇ

Deakin University, Geelong, VIC, Australia

Abstract

View references (47)

This study evaluated self-esteem and emotional regulation as possible mediators of the relationship between authoritative parenting and sociopolitical control in 240 low socioeconomic youths, aged 10 to 16 years $(M=12.48$ years, $S D=1.33$ years; 122 males, 118 females). Participants completed self-report questionnaires assessing their self-esteem, emotional regulation, perception of sociopolitical control, and perceptions of their parents' supportive parenting and behavior monitoring. The relationship between authoritative parenting and perception of sociopolitical control was mediated by self-esteem and emotiona regulation cognitive reappraisal skills. The relationship between authoritative parenting and self-esteem was moderated by gender, in that, authoritative parenting was more predictive of self-esteem in male youth than female youth. This
References (47)

View in search results format

$\square$ All

$\square$ I Barber, B.K., Chadwick, B.A., Oerter, R.

Parental behaviors and adolescent self-esteem in the United States and Germany

(1992) Journal of Marriage and Family, 54, pp. 128-141. Cited 48 times.

$\square 2$ Bariola, E., Gullone, E., Hughes, E.K.

Child and Adolescent Emotion Regulation: The Role of Parental Emotion Regulation and Expression

(2011) Clinical Child and Family Psychology Review, 14 (2), pp. 198-212. Cited 71 times. doi: 10.1007/s10567-011-0092-5

Full Text View at Publisher

$\square 3$ Bean, R.A., Bush, K.R.,McKenry, P.C., Wilson, S.M.

The impact of parental support, behavioral control, and psychological control on the academic achievement and self-esteem of African American and European American adolescents

(2003) Journal of Adolescent Research, 18 (5), pp. 523-541. Cited 129 times. doi: $10.1177 / 0743558403255070$

Full Text View at Publisher

$\square 4$ Bleidorn, W., Arslan, R.C., Denissen, J.J.A., Rentfrow, P.J., Gebauer, J.E., Potter, J., Gosling, S.D. Age and gender differences in self-esteem $A$ cross-cultural window

En este ítem, 36 de las 47 referencias $(=77 \%)$ se compararon con un ítem ya existente en Scopus. Esto significa que estos artículos (más sus perfiles de autor y afiliación acompañantes) reciben una actualización semanal (o a veces mensual) de sus citas (cited by) mucho más pronto que con el AiPs sin referencias. Este es un importante paso adelante, de acuerdo también con los datos que publica Dimensions en sus AiPs con las referencias desde el principio. 
Editor FECYT 


\section{Editor FECYT}

Ahora es más fácil para los usuarios de Scopus en España descargar su currículum en formato CVN. Los usuarios que se conectan desde una cuenta de España, pueden descargar el CVN desde la página de detalles del autor:

Search Sources Alerts Lists Help $\vee$ SciVal $\pi$

\section{Author details}

Presani, Eleonora

Foundation for Fundamental Research on Matter, Utrecht,

Netherlands
Author ID: 26421798800

(DD http://orcid.org/0000-0001-7995-1455

Other name formats: Presani, E.

Subject area:

\section{B}

Document
trends:

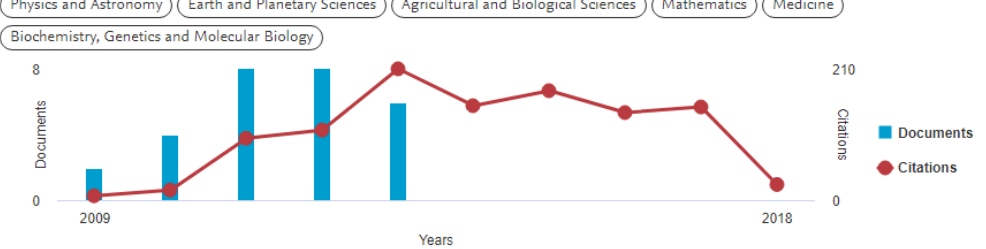

$\triangle$ Get citation alerts + Add to ORCID (3) is Request author detail corrections $\rightarrow$ Export profile to Scival E⿱ Ex Export to FECYT CVN

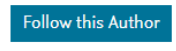

View potential author matches

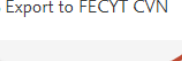

Al hacer clic en el botón Export to FECYT CVN, se les guiará a través del Asistente de autor, para revisar todos los documentos que pertenecen a su perfil, así como la afiliación y su nombre.

Total citations 1084 by $57:$

https://service.elsevier.com/app/answers/detail/a id/12034/kw/spain\%20cvn/supporthub/scopus/ 


\section{Editor FECYT}

En el último paso, a los usuarios se les ofrece el enlace para descargar el CVN y pueden elegir si desean descargarlo en español o en inglés.

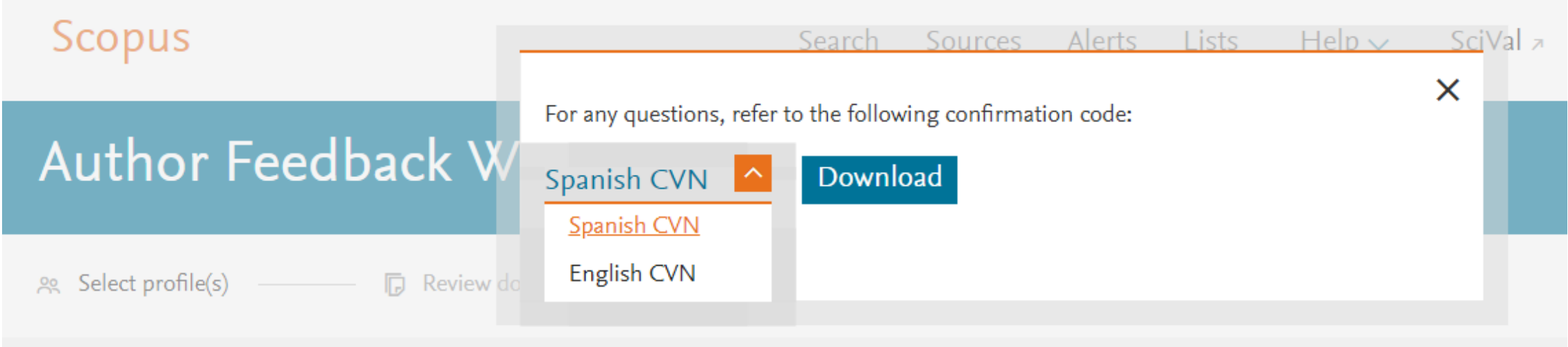

$\checkmark$ You have successfully submitted your request. If your CVN file didn't download, click here to download it.

\section{Profile}

Presani, Eleonora Preferred Name

\section{Affiliation}

The author's affiliation is:

FOM-Institute of Subatomic Physic 
Más Información

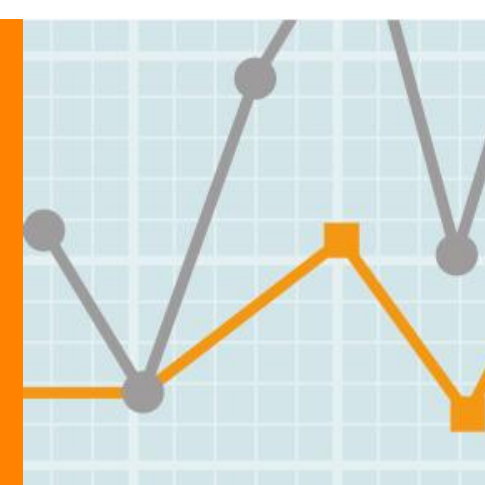




\section{En caso de duda puede contactar con:}

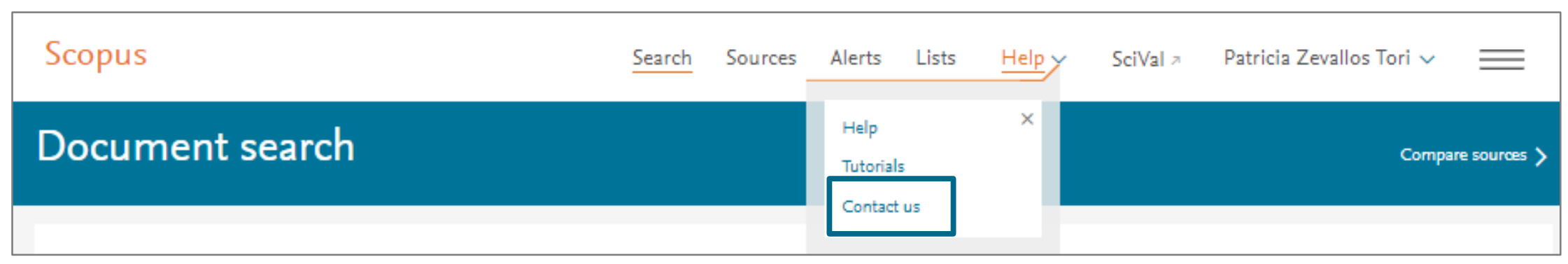

ELSEVIER
Scopus Support Center




\section{Dónde encontrar más informacíón:} Scopus Blog, Newsletter, Twitter, y el Info Site
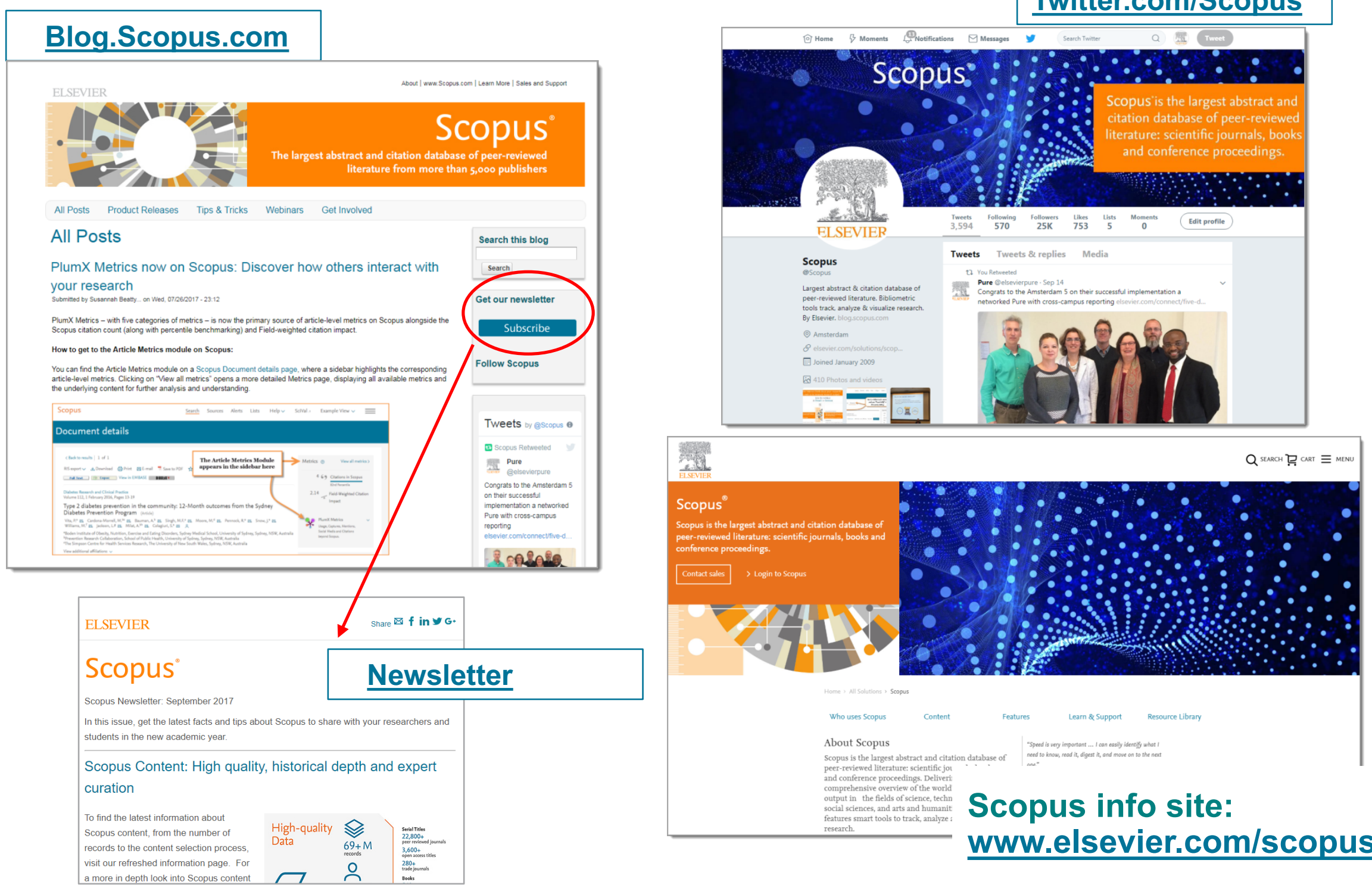

Scopus info site: www.elsevier.com/scopus 


\section{Research Intelligence}

\section{¡Muchas gracias!}

\section{recursoscientificos@fecyt.es}

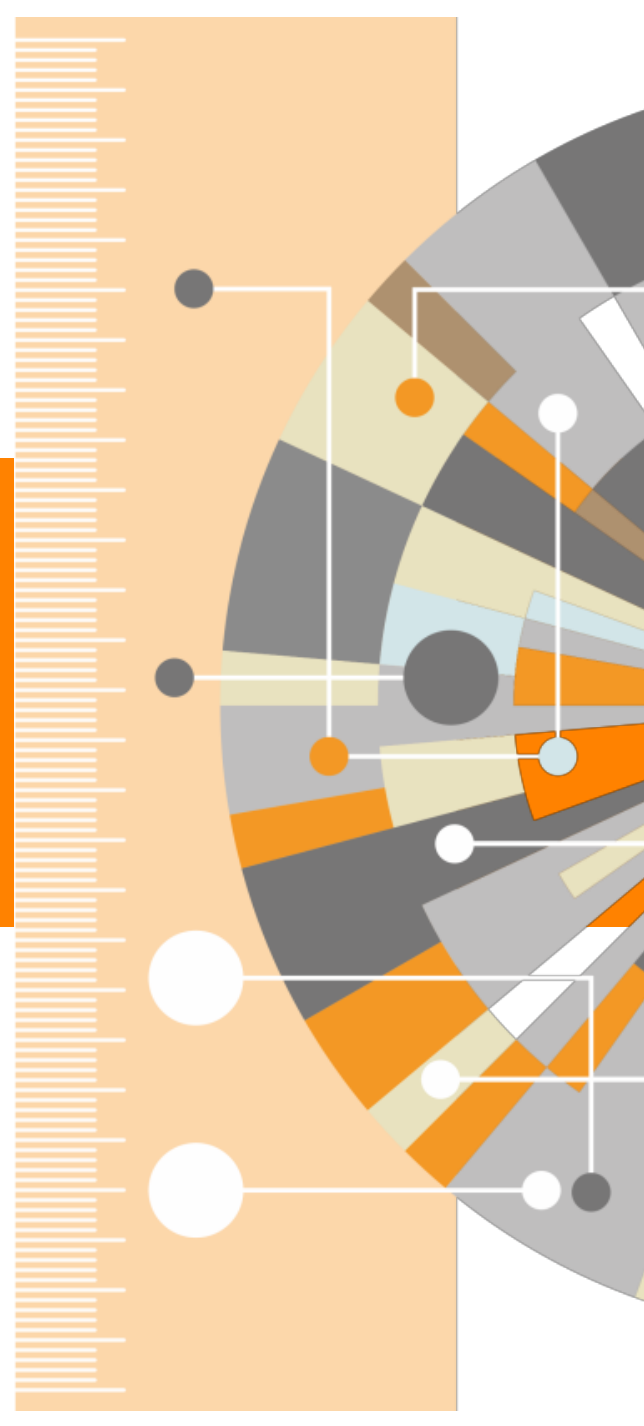

